\title{
Assessment of HF Radar in Mapping Surface Currents under Different Sea States
}

\author{
Guomei Wei, Zhigang He, Yanshuang Xie, Shaoping Shang, Hao Dai, Jingyu Wu, \\ KE LiU, AND RUi LiN \\ College of Ocean and Earth Sciences, and Research and Development Center for Ocean Observation Technologies, and Key \\ Laboratory of Underwater Acoustic Communication and Marine Information Technology, Ministry of Education, Xiamen \\ University, Xiamen, China
}

YAN WAN, HANG LIN, AND JINRUI CHEN

Fujian Marine Forecasts, Fuzhou, China

YAN LI

Dongshan Swire Marine Station, Xiamen University, Xiamen, China

(Manuscript received 7 August 2019, in final form 16 June 2020)

\begin{abstract}
Two Ocean State Monitoring and Analyzing Radar (OSMAR071) (7.8 MHz) high-frequency (HF) radars and four moored ADCPs were operated concurrently in the southwestern Taiwan Strait during JanuaryMarch 2013. Qualitative and quantitative comparisons of surface currents were conducted between the HF radars and the ADCPs. Except for a location probably affected by shallow water and sand waves on the Taiwan Banks, the HF-radar-derived radial currents (radials) showed good agreement with the ADCP measured results (correlation coefficient: $0.89-0.98$; rms difference: $0.07-0.13 \mathrm{~m} \mathrm{~s}^{-1}$ ). To provide further insight into the geophysical processes involved, the performance of the HF-radar-derived radials was further evaluated under different sea states (sea states: 2-6). It was found that both the data returns of the radar-derived radials and the differences between the radar-derived radials and the ADCP-derived radials varied with sea state. The HF radar performed best at sea state 4 in terms of data returns. The spatial coverage increased rapidly as the waves increased from sea state 2 to 4 . However, it decreased slowly from sea state 4 to 6 . Second, the radial differences were relatively high under lower sea states ( 2 and 3 ) at the location where the best agreement was obtained between the radar and ADCP radials, whereas the differences increased as the sea states increased at the other three locations. The differences between the radials measured by the HF radars and the ADCPs could be attributed to wave-induced Stokes drift and spatial sampling differences.
\end{abstract}

\section{Introduction}

High-frequency (HF) radio waves $(3-30 \mathrm{MHz})$ are radiated by a vertically polarized antenna. The loss of energy of such electromagnetic waves is small when the waves propagate along the conductive sea surface. The Bragg resonant backscattering of electromagnetic waves reflected from the sea surface was first explained by Crombie (1955). By exploiting the phenomenon of Bragg resonant backscattering and the Doppler shift effect, HF radar is capable of remote measurement of ocean surface

Corresponding author: Shaoping Shang, spshang@xmu.edu.cn currents (Stewart and Joy 1974; Barrick et al. 1977) and sea states (Hasselmann 1971; Barrick 1977).

Many studies have been conducted to evaluate the performance of HF radar in mapping surface currents through comparison with in situ observations (e.g., Emery et al. 2004; Essen and Gurgel 2000; Hammond et al. 1987; Liu et al. 2010, 2014; Ohlmann et al. 2007; Paduan and Rosenfeld 1996; Paduan et al. 2006; Shay et al. 2002). Reasonable agreement was found between currents derived by HF radar and currents measured by other approaches, such as current meters and drifters. Shore-based HF radar is considered satisfactory for routine observation of coastal surface currents (Paduan and Washburn 2013, and references therein). The sources 
responsible for the observed differences and errors in HF radar current measurements was reviewed, as well as the limitations introduced by validation methods (e.g., Graber et al. 1997; Emery et al. 2004).

Despite the great efforts that have been made, the source of differences and errors between ocean current measured by HF radar and near-surface current meters remains a crucial issue. The comparison of currents measured with HF radar and near-surface current meters is subject to numerous sources of differences and errors beyond those of the instruments (Emery et al. 2004; Graber et al. 1997; Kohut et al. 2006, 2012; Liu et al. 2014). Results reported by Graber et al. (1997) suggest that $32 \%-50 \%$ of the rms difference between current derived by HF radar and near-surface current meters can be explained in terms of the contributions from collocation and concurrence differences and three geophysical processes. Kohut et al. (2006) studied the effects of environmental variability based on ADCPrecorded currents in the Mid-Atlantic Bight and found that the flow environment variability dominated the rms difference between the HF radar and ADCP radials. Also, the contribution of vertical and horizontal variability to the rms difference could vary with different wind condition. Liu et al. (2014) examined the horizontal and vertical variability of the near-surface current velocity on the West Florida shelf, and found a substantial proportion $(80 \%-100 \%)$ of the observed differences between $\mathrm{HF}$ radar and ADCP velocity measurements could be explained by the horizontal and vertical sampling differences between sensors.

In addition to the differences induced by environmental variability, the contribution of wave-induced Stokes drift should also be considered. However, certain controversy exists regarding the ability of HF radar to measure Stokes drift. Typically, HF radar current measurements employ the dispersion relation of linear waves (Barrick 1972; Stewart and Joy 1974); that is, the phase velocity of Bragg waves in deep water can be estimated as follows:

$$
v_{p}= \pm \sqrt{\frac{g}{k_{B}}}
$$

where $g$ is the acceleration of gravity and $k_{B}$ is the Bragg wavenumber. However, some studies argued that nonlinear effects also play an important role in HF radar current measurements (Barrick and Weber 1977; Ardhuin et al. 2009). In other words, radar-derived currents include the wave-induced Stokes drift. However, previous studies are inconsistent regarding the existence and extent of the contribution of Stokes drift to HF radar current measurements, both theoretically and experimentally. It has been suggested that radar-derived currents include all (Graber et al. 1997; Laws 2001), some (Ardhuin et al. 2009), or none of the wave-induced Stokes drift (Röhrs et al. 2015). Recently, Chavanne (2018) reviewed the theoretical and experimental results that had been reported in the literature and confirmed that HF radars measure the surface Stokes drift or the weighted depthaveraged Stokes drift.

The importance of waves is related to the way in which HF radar senses ocean surface currents. However, specific explanation of how various sources of errors and differences under different sea conditions influence the accuracy of radar-derived currents is absent. Hence, the emphasis of this study is to evaluate the performances of HF radar under different sea states. The main influencing factors-for example, vertical variability of current, Stokes drift, and sea bottom topography-were analyzed to provide insight into the physical processes involved in HF radar current measurements. This is useful for improving accuracy of numerical modeling (Breivik and Sætra 2001; Zhang et al. 2010) and will be of benefit in practical applications, for example, searchand-rescue operations and oil spill mitigation (Abascal et al. 2009; Breivik et al. 2013).

\section{Materials and methods}

\section{a. HF-radar-derived current}

In China, the study of HF radar in ocean surface currents and sea state monitoring was conducted from the late 1980s, and the first HF radar system was developed for ocean surface state surveillance by researchers of Wuhan University in 1993. Many subsequent validation studies have contributed to the growing acceptance and wide use of the series of Ocean State Monitoring and Analyzing Radar (OSMAR) systems in China (Hou et al. 1997; Lai et al. 2017, 2018; Liu et al. 2007; Wu et al. 2001; Wu et al. 2009; Yang et al. 2005). The OSMAR071 HF radar is the product developed by Wuhan University and the China Precise Ocean Detection Technology Co., Ltd. During January-March 2013, two OSMAR071 HF radars were deployed on the coast of Dongshan County (DOSA) and Longhai County (LOHI) of Fujian Province (Fig. 1) to observe ocean surface currents in the southwestern Taiwan Strait. The OSMAR071 employs a frequencymodulated interrupted continuous waveform operating at $7.8 \mathrm{MHz}$ with a $30-\mathrm{kHz}$ bandwidth. An OSMAR071 system is composed of two separate antenna arrays: an eight-element nonlinear receiving array and a threeelement Yagi-Uda antenna for transmitting the continuous waveform pulses. Based on the multiple signal classification (MUSIC) spatial superresolution algorithm 


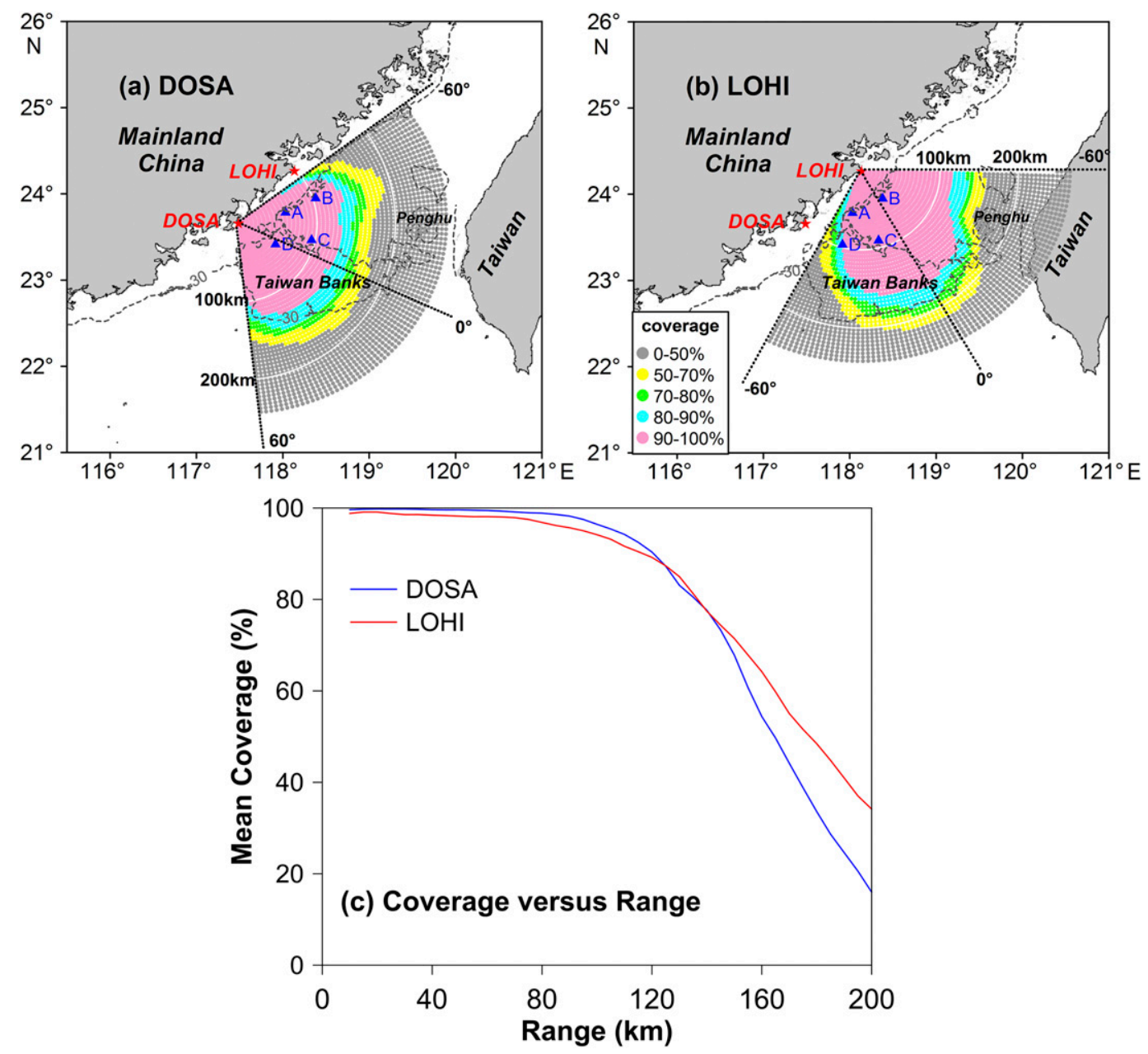

FIG. 1. Spatial coverage of radial currents (radials) derived by OSMAR071 HF radar during January-March 2013: (a) DOSA and (b) LOHI. Stars indicate radar sites, and triangles indicate locations of the buoys. Water depths (grid resolution: $0.8 \mathrm{~min}$ ) were downloaded from General Bathymetric Chart of the Oceans (GEBCO; http://www.gebco.net). (c) Mean coverage of sample cells at the same range vs range over the sample duration.

(Schmidt 1986; Barrick and Lipa 1999; Yang et al. 2005), an OSMAR071 system can measure radials with range and bearing resolutions of $5 \mathrm{~km}$ and $1.5^{\circ}$, respectively. A vector current map of the overlapping region is derived by combining two or more radial maps measured by concurrently operating HF radars (Graber et al. 1997). Here, the DOSA and LOHI radials were used to map vector currents with spatial resolution of $0.025^{\circ} \mathrm{N} \times$ $0.025^{\circ} \mathrm{E}$. These two radars sampled the signal in a sweep period of $0.6528 \mathrm{~s}$. Every 1024 sweep periods were coherently integrated to map radial velocity, so the time required for a radial current map was 11-min. Last, the temporal resolution of the radar-derived radials and vector currents was set as $10 \mathrm{~min}$.

An OSMAR071 is capable of measuring surface currents within a $200-\mathrm{km}$ range. The two radars deployed at DOSA and LOHI overlooked the southwestern Taiwan
Strait. The Taiwan Banks (TB) is an area with relatively shallow water depth (mostly 10-35 m) that is located in the south of the detection region of the two radars and extends from the west near Dongshan County to the east of the Penghu Islands (Fig. 1). Zhang et al. (2014) claimed that $43 \%$ of the area within the TB has water depth of $20-30 \mathrm{~m}$, and that approximately $38 \%$ of the area, located mainly in the western TB, has water depth of $10-20 \mathrm{~m}$. Particularly, about $2 \%$ of the area has water depth of $0-10 \mathrm{~m}$, which is near or below the deep water criteria of the 19-m Bragg wave. The seabed of the TB is covered extensively by sand waves with maximum height of $>20 \mathrm{~m}$ (Shao et al. 2011; Zhang et al. 2014).

\section{b. ADCP-recorded current}

Four 3-m discus buoys were deployed within the HF radar radial coverage (i.e., within the range of $100 \mathrm{~km}$ ) 
TABLE 1. Information on in situ observations. Information about the bearing and the boresight beam of the receiving array for the two radars is presented in section 3 a.

\begin{tabular}{|c|c|c|c|c|c|c|c|c|c|c|}
\hline \multirow[b]{2}{*}{ Stations } & \multirow[b]{2}{*}{ Lon $\left({ }^{\circ} \mathrm{E}\right)$} & \multirow[b]{2}{*}{ Lat $\left({ }^{\circ} \mathrm{N}\right)$} & \multirow[b]{2}{*}{$\begin{array}{c}\text { Water } \\
\text { depth (m) }\end{array}$} & \multicolumn{2}{|c|}{ DOSA } & \multicolumn{2}{|c|}{ LOHI } & \multirow[b]{2}{*}{ Obs time } & \multirow[b]{2}{*}{ Parameter } & \multirow[b]{2}{*}{$\begin{array}{c}\text { Valid data after } \\
\text { QC }(\%)\end{array}$} \\
\hline & & & & $\begin{array}{c}\text { Range } \\
(\mathrm{km})\end{array}$ & $\begin{array}{c}\text { Bearing } \\
\left({ }^{\circ}\right)\end{array}$ & $\begin{array}{c}\text { Range } \\
(\mathrm{km})\end{array}$ & $\begin{array}{c}\text { Bearing } \\
\left({ }^{\circ}\right)\end{array}$ & & & \\
\hline $\mathrm{A}$ & 118.0317 & 23.7840 & 38 & 57.5 & -37.1 & 54 & 42.2 & 29 Jan-15 Mar 2013 & $\begin{array}{l}\text { Current } \\
\text { Hs }\end{array}$ & $\begin{array}{l}100 \\
100\end{array}$ \\
\hline B & 118.3803 & 23.9502 & 46 & 97 & -42.2 & 43 & -7.9 & 29 Jan-8 Mar 2013 & $\begin{array}{c}\text { Wind } \\
\text { Current } \\
\text { Hs } \\
\text { Wind }\end{array}$ & $\begin{array}{l}100 \\
100 \\
48.2 \\
83.2\end{array}$ \\
\hline $\mathrm{C}$ & 118.3327 & 23. 4633 & 38 & 90 & -11.1 & 91 & 16.2 & 29 Jan-15 Mar 2013 & $\begin{array}{l}\text { Current } \\
\text { Hs } \\
\text { Wind }\end{array}$ & $\begin{array}{l}100 \\
100 \\
100\end{array}$ \\
\hline $\mathrm{D}$ & 117.9153 & 23.4157 & 29 & 51 & 5.4 & 97 & 44.5 & 29 Jan-7 Mar 2013 & $\begin{array}{c}\text { Current } \\
\text { Hs } \\
\text { Wind }\end{array}$ & $\begin{array}{l}100 \\
99.8 \\
99.8\end{array}$ \\
\hline
\end{tabular}

during January-March 2013 (see Fig. 1 and Table 1). Two buoys were deployed at locations (station A and C) almost equidistant from DOSA and LOHI. With greater distance from both radar sites, station $\mathrm{C}$ was located at the center of the detection area of the two radars. station B was close to LOHI but far from DOSA. Located in the TB area, station D was close to DOSA but far from LOHI.

With $1-\mathrm{MHz}$ transmitting frequency, a downwardlooking Nortek ADCP (Aquadopp) was integrated in each discus buoy. The data collected by the ADCPs were transmitted in real time. The ADCP current velocities, which were measured at depths of $1.5-11.5 \mathrm{~m}$ in 0.5-m bins, were recorded every $5 \mathrm{~min}$ (data were collected over 1-min periods). The shell of the buoy at station $\mathrm{C}$ was made of polymer material, whereas that at stations A, B, and $\mathrm{D}$ was made of ferrous material. Because ferrous material may have an effect on the accuracy of the ADCPrecorded current directions through magnetic deviation, the current direction at stations $\mathrm{A}, \mathrm{B}$ and $\mathrm{D}$, was corrected effectively based on an error model (Dai et al. 2016).

\section{c. Other data}

Significant wave height $(\mathrm{Hs})$ and wind vector were involved in this study. The wave sensor is a product of the Institute of Oceanographic Instrumentation, Shandong Academy of Sciences, China, which uses a variety of combinations of accelerometers, tilt and rotation sensors, and compasses to compute wave characteristics. The wind sensor (YOUNG 05103) is a product of the R. M. Young Company. Both wave and wind sensors were integrated in the discus buoys. The observed wave and wind data were recorded every $30 \mathrm{~min}$ with 17 - and $10-\mathrm{min}$ observation periods, respectively.

All wind and wave data collected by the four buoys underwent quality control (QC). First, QC was conducted for wind data collected concurrently at stations A-D. Channel effect modification means the wind direction in the Taiwan Strait is reasonably stable and generally aligned with the Taiwan Strait during the winter monsoon (Guo et al. 2010). Hence, QC was conducted based on correlation analysis of the wind vectors at different locations. It was found that the wind direction data at station B were not in acceptable quality during 2-7 March 2013. After the removal of those bad data, the time series of wind vectors at the four buoys exhibited reasonable consistency; that is, the complex correlation coefficients between any two different stations were all $>0.96$ [see Kundu (1976) for further details regarding the complex correlation coefficient]. Second, QC for in situ Hs was performed based on approved wind speed data from the same buoy. Other than the period of blank values at station B during 17 February-8 March, strong correlation was found between Hs and wind speed, as expected [correlation coefficient $(\mathrm{CC}):>0.89$ ], indicating that the Hs data at the four locations were adequate for further use.

\section{d. Statistical metrics}

As a widely used statistical method, the $\mathrm{CC}$ provides quantitative measurement of the level of agreement between two scalar time series. The mean bias (MB), mean absolute difference (MAD), and rms difference (RMSD) are also used commonly to represent the magnitude of the differences between two different datasets:

$$
\begin{aligned}
\mathrm{MB} & =\frac{1}{N} \sum_{i=1}^{N}\left(y_{i}-x_{i}\right), \\
\mathrm{MAD} & =\frac{1}{N_{i}} \sum_{i=1}^{N}\left|y_{i}-x_{i}\right|, \quad \text { and }
\end{aligned}
$$




$$
\mathrm{RMSD}=\sqrt{\frac{1}{N_{i=1}^{N}\left(y_{i}-x_{i}\right)^{2}} .}
$$

Here, $y_{i}$ and $x_{i}$ represent the radar-derived current (radials) and the ADCP-recorded current (radials), respectively, and parameter $N$ represents the total number of matched observations.

\section{Performance evaluation of OSMAR071}

\section{a. Radial current data returns}

Data return is an important performance metric of an HF radar used for mapping surface currents. One commonly used indicator of data return is the spatial coverage of radials achieved over the sample duration (Fig. 1). The spatial coverage (percent coverage) was defined as the number of valid data divided by the total number of theoretical measurements. When the signalto-noise ratio of the first-order sea echo satisfied a predefined threshold ( $5 \mathrm{~dB}$ for the OSMAR071), it was considered that the acquired data point was valid. It was noted that the LOHI radar did not report valid data on either 8 February or 15 March 2013 because of shortterm power interruption. Therefore, these two days were excluded from the computation of the spatial coverage of LOHI shown in Fig. 1.

The boresight beam of the receiving array for DOSA and LOHI was centered at the azimuth angle of $114^{\circ}$ and $150^{\circ}$, respectively. For convenience of discussion, bearings to the left and right of the boresight beam are defined as negative and positive angles, respectively. The bearing of the sample cells ranged from $-60^{\circ}$ to $+60^{\circ}$. For sample cells at the same range, the coverage of cells with relatively small bearings was higher than cells with larger bearings; that is, coverage decreased as the bearing increased. The spatial coverage of the LOHI radials (Fig. 1b) was found to have uneven distribution across the bearing angles. For sample cells at the same range, the LOHI radar tended to have lower spatial coverage in the southwest of the sector than in other areas, probably because of the effect of a nearby hill to the right of the radar.

The spatial coverage decreased as the range (i.e., the distance between a sample cell and the radar site) increased. Both radars had higher spatial coverage near the radar site than in the outer band of the radar footprint, as expected. To obtain the mean coverage at a certain range, the percent coverage of sample cells over all bearings from $-60^{\circ}$ to $+60^{\circ}$ was averaged. Within the range of $120 \mathrm{~km}$, the mean coverage exceeded $90 \%$. In particular, the mean coverage exceeded $95 \%$ within the range of $100 \mathrm{~km}$. However, the mean coverage decreased markedly as the range increased beyond $100 \mathrm{~km}$, with the rate of decrease being greater for the DOSA radar. The mean coverage declined from $96 \%$ at $100-\mathrm{km}$ range to $16 \%$ at $200-\mathrm{km}$ range for the DOSA radar and from $95 \%$ to $34 \%$ for the LOHI radar.

\section{b. Comparison of HF radar and ADCP radial currents}

The performance of radar-derived radials was evaluated by comparison with ADCP-derived radials. The ADCP-recorded current vectors were projected into the direction of the mooring's bearing angle to the HF radar site origin to obtain the ADCP-derived radials [see Fig. 2 in Graber et al. (1997) for further details about the relationship between a vector current and two intersecting radials]. The ADCP-derived radials were then compared directly with those observed by the radars. The depths of the ADCP bins ranged from 1.5 to $11.5 \mathrm{~m}$ at the four buoy locations. Comparison of the radarderived radials with the vertical ADCP-derived radials is shown in Fig. 2 for sampled durations when both radar and in situ data were available and deemed valid. The comparison results of the vertical profiles exhibit reasonable consistency between the HF radar and ADCP radials at stations $\mathrm{A}-\mathrm{C}(\mathrm{CC}>0.87)$. The similar results of $\mathrm{CC}$ and RMSD obtained for different ADCP bins indicate homogeneous velocity profiles at stations $\mathrm{A}$ and $\mathrm{C}$. However, inhomogeneous velocity profiles were found at stations B and $\mathrm{D}$, especially for the depths of $\mathrm{ADCP}$ bins in the range $1.5-3.5 \mathrm{~m}$, with comparatively bigger differences in relation to the other ADCP bins. Moreover, the comparison results of the vertical profiles at station $\mathrm{D}$ indicate lower correlation between the DOSA radar-derived radials and ADCP-derived radials (CC: 0.42-0.59).

According to Stewart and Joy (1974), the effective depth of radar measurements can be defined as $\lambda /(8 \pi)$ (where $\lambda$ is the radio wavelength). Thus, 7.8-MHz radars estimate radials at an effective depth of $1.5 \mathrm{~m}$. Hence, the ADCP-derived radials of the topmost bin $(1.5 \mathrm{~m})$ were used to evaluate the radials observed by the radars at stations A-C. However, the currents at station D were probably influenced by the shallow waters and submarine sand waves on the TB, especially the nearsurface currents (Shao et al. 2011; Zhang et al. 2012). Consequently, the ADCP bin of $3.5 \mathrm{~m}$, that is, the uppermost bin of the relatively homogeneous velocity profile with relatively higher CC and lower RMSD (Fig. 2), was used to evaluate the radar-derived radials at station D.

All 10-min time series of radar and ADCP radials at these locations are shown in Fig. 3. The discontinuous time series of LOHI radials was due to short-term power interruption. Except for the comparison of DOSA radials at station $\mathrm{D}$, the time series data of radials observed by 

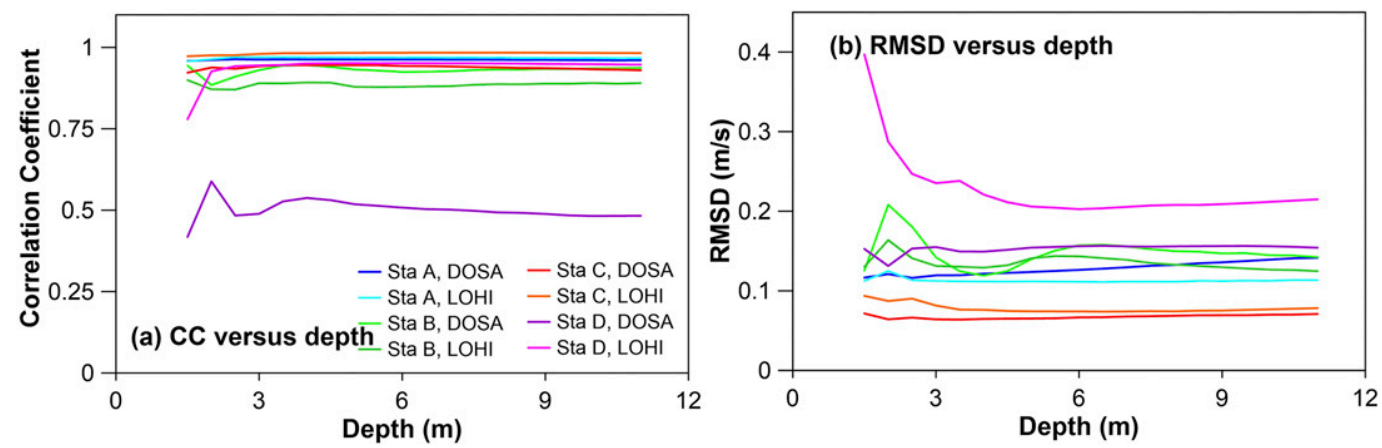

FIG. 2. (a) Correlation coefficient and (b) RMSD between HF radar and ADCP radial currents as a function of depth of ADCP bin.

the radar exhibit reasonable consistency with the ADCPs (CC: 0.89-0.99). However, the absolute values of radarderived radials of LOHI were generally underestimated at station $\mathrm{B}$ when the radial velocities were $<0 \mathrm{~m} \mathrm{~s}^{-1}$, whereas they were obviously overestimated at station D. The amplitude of radar-derived radial velocities of DOSA was apparently smaller than that of the ADCPderived radial velocities at station $\mathrm{D}$, and a relatively small CC value (0.53) was found for the results of the radar-ADCP comparisons.

Statistics of the comparison between radar and ADCP radials (Table 2) show the $\mathrm{MB}$ was from -0.01 to $0.07 \mathrm{~m} \mathrm{~s}^{-1}$, MAD was $0.05-0.10 \mathrm{~m} \mathrm{~s}^{-1}$, and RMSD was $0.07-0.13 \mathrm{~m} \mathrm{~s}^{-1}$ (except for station D). Despite the greater distances between station $\mathrm{C}$ and the two radars (Fig. 1 and Table 1), the differences in the radar-ADCP comparison at station $\mathrm{C}$ are smaller than at the other buoy locations. Moreover, the differences at station A are smaller than at station B. It is inferred that these results might be partially influenced by the real current profile. The relatively larger errors were found at station D (RMSD of 0.15 and $0.24 \mathrm{~m} \mathrm{~s}^{-1}$ for DOSA and LOHI radials, respectively) located in the sand waves dominated TB area.

In view of the inherent differences between the HF radars and ADCPs (e.g., different measuring mechanisms; collocation and concurrence differences), the comparison results indicated that the reliability of the radar-derived radials was satisfactory.

\section{c. Expected differences between $\mathrm{HF}$ radar and $A D C P$ radial currents}

Owing to the significant differences between the sampling of the HF radars and ADCPs in the horizontal and vertical, the expected differences caused by environmental variability must be quantified before any evaluation of the quality of the HF radar surface current estimates (Kohut et al. 2006, 2012; Liu et al. 2014).

According to Stewart and Joy (1974), 7.8-MHz radar measures radials within the upper $1.5 \mathrm{~m}$ of the water column. To determine the magnitude of the expected vertical differences in our study area, we calculated the RMSD of radials in the ADCP topmost bin with bins $1 \mathrm{~m}$ deeper for stations $\mathrm{A}-\mathrm{C}$ and $2 \mathrm{~m}$ deeper for station D (Table 3). The RMSD values were found to be within $0.056-0.071,0.069-0.096,0.045-0.055$, and 0.080 $0.217 \mathrm{~m} \mathrm{~s}^{-1}$, respectively, for stations A-D. In comparison with the RMSD of the eight radar-ADCP station pairs shown in Table 2, we found the vertical shear significantly influenced the differences between the radar and ADCP radials; that is, the differences increased with increasing vertical shear. A rough estimate indicated that $48 \%-77 \%$ of the observed differences between the HF radar and ADCP radials might be explained in terms of the vertical variability at stations A-C, while a larger proportion $(75 \%-91 \%)$ was found for the LOHI radials at station D. We note that these RMSD values are larger than found in previous study (Kohut et al. 2012; Liu et al. 2014). The larger vertical shear might be attributable to the shallower ADCP bins used in our study, which could introduce higher wind-driven shear.

\section{Dependence of OSMAR071 performance on sea state}

To enrich the understanding of the geophysical processes involved, the performance of the radar-derived radials was evaluated further based on the ADCP-derived radials under different sea state conditions. Since there were limited data record when Hs was high ( $\geq 4 \mathrm{~m}$ ), we chose to convert Hs to sea state using Douglas sea scale (Schule 1966), so we may get more match-ups of the radar-derived radials and ADCPderived radials to ensure statistical significance.

\section{a. Wave energy and sea states}

First the relationship between wave energy and sea state was examined, to make sure sea state could be a reasonable alternative proxy. 


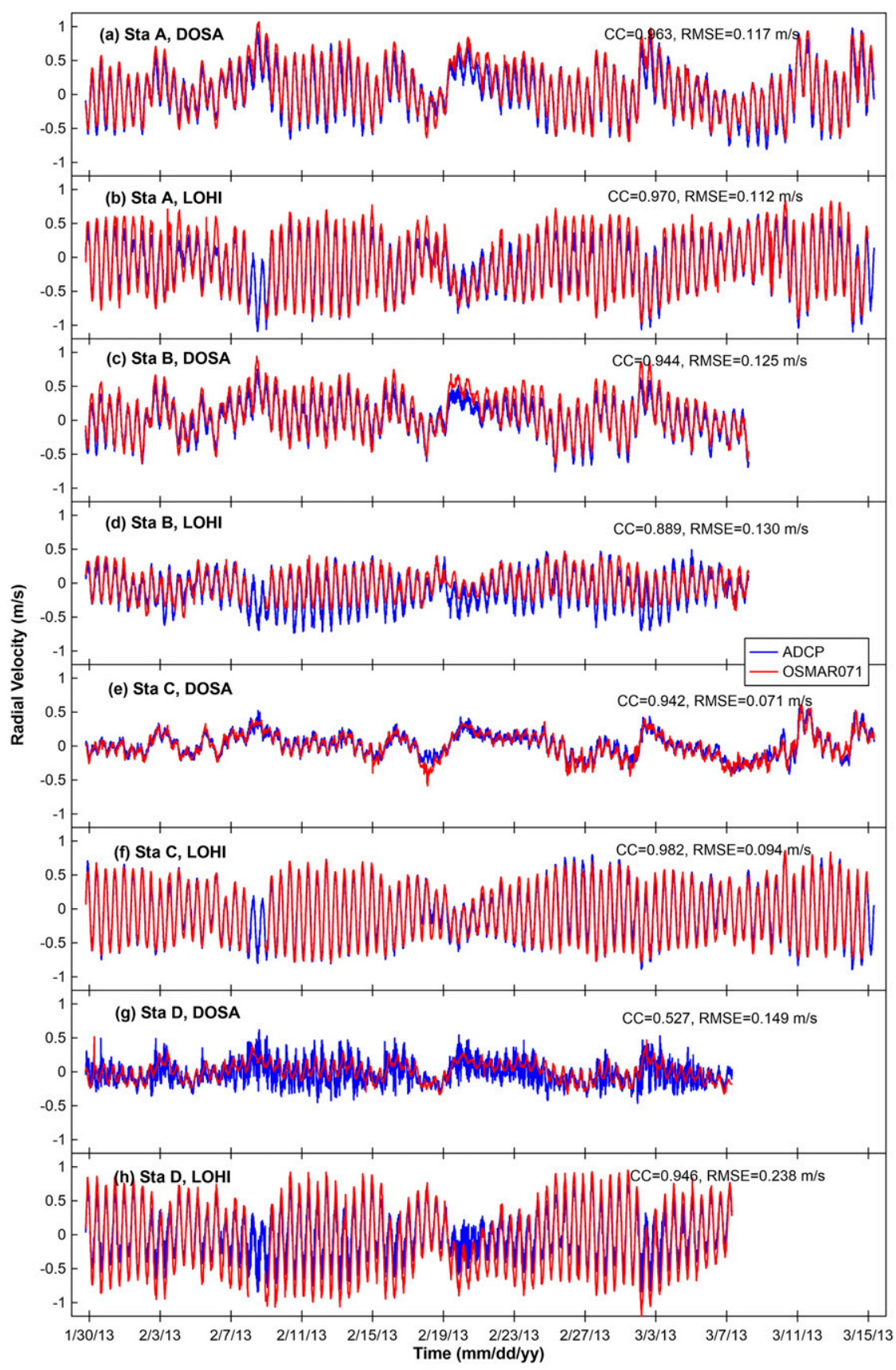

FIG. 3. Comparison of radial currents between HF radars and ADCPs. Statistics (CC and RMSD) are shown in the top-right corner of each panel.

The signal recorded by HF radar is dominated by Bragg waves with half the electromagnetic wavelength. To investigate how waves at the frequency of $19-\mathrm{m}$ Bragg waves $(f=0.2865 \mathrm{~Hz})$ varied in response to changing sea state conditions, wave spectra were analyzed at the four locations. However, without in situ wave spectra within the HF radar domain, model-simulated spectra were analyzed.
Previous research has proven that the Simulating Wave Nearshore (SWAN) model (Booij et al. 1999) has acceptable performance in wave simulation in the Taiwan Strait (Cai et al. 2019). Therefore, we used simulation results of the SWAN model (version 40.85) to investigate how waves at $0.2865 \mathrm{~Hz}$ might react to different wind speeds. The model was implemented in the same way as in a previous experiment (Cai et al. 2019). 
TABLE 2. Comparison statistics of radial currents between HF radars and ADCPs.

\begin{tabular}{|c|c|c|c|c|c|c|}
\hline \multicolumn{2}{|c|}{ Station } & \multirow{2}{*}{$\frac{\begin{array}{c}\mathrm{MB} \\
\left(\mathrm{m} \mathrm{s}^{-1}\right)\end{array}}{0.054}$} & \multirow{2}{*}{$\begin{array}{c}\begin{array}{c}\text { MAD } \\
\left(\mathrm{m} \mathrm{s}^{-1}\right)\end{array} \\
0.091\end{array}$} & \multirow{2}{*}{$\begin{array}{c}\begin{array}{c}\text { RMSD } \\
\left(\mathrm{m} \mathrm{s}^{-1}\right)\end{array} \\
0.117\end{array}$} & \multirow{2}{*}{$\frac{\mathrm{CC}}{0.963}$} & \multirow{2}{*}{$\frac{N}{6238}$} \\
\hline A & DOSA & & & & & \\
\hline & LOHI & 0.016 & 0.085 & 0.112 & 0.970 & 5922 \\
\hline \multirow[t]{2}{*}{ B } & DOSA & 0.063 & 0.100 & 0.125 & 0.944 & 5209 \\
\hline & LOHI & 0.067 & 0.104 & 0.130 & 0.889 & 5054 \\
\hline \multirow[t]{2}{*}{$\mathrm{C}$} & DOSA & -0.011 & 0.052 & 0.071 & 0.942 & 6190 \\
\hline & LOHI & -0.009 & 0.071 & 0.094 & 0.982 & 5984 \\
\hline \multirow[t]{2}{*}{$\mathrm{D}$} & DOSA & 0.036 & 0.110 & 0.149 & 0.527 & 5087 \\
\hline & LOHI & -0.100 & 0.197 & 0.238 & 0.946 & 4737 \\
\hline
\end{tabular}

We assessed the accuracy of the model-predicted Hs based on in situ Hs observed simultaneously by the four buoys located at stations A-D (Fig. 4). Albeit with slight underestimation $(\mathrm{MB}=-0.38 \mathrm{~m} ; \mathrm{RMSD}=0.54 \mathrm{~m})$, the Hs predicted by model exhibited reasonable consistency with that of the buoys with $\mathrm{CC}>0.95$. The basic equation of the SWAN model is the spectral action balance equation (Booij et al. 1999). Following the theory of error propagation, the simulated wave spectra could be considered acceptable for use within the HF radar domain.

Wave spectral data at the Bragg wavelength were generated using the SWAN model for the period January-March 2013. Comparison of the wave energy density and the corresponding wind speed conditions is shown in Fig. 5. It can be seen that the features of the data trends are similar at all four locations; that is, the wave energy increases nonlinearly with wind speed. At lower and higher wind speeds, the wave energy increases slowly. When wind speed is approximately $6-11 \mathrm{~m} \mathrm{~s}^{-1}$, the wave energy increases more rapidly. These results are similar to the findings of Shen et al. (2012), who found that wave energy increased nearly linearly with wind speed until saturated at approximately $15 \mathrm{~m} \mathrm{~s}^{-1}$ for the frequency of 19.8-m Bragg waves in the North Sea.

The relationship between in situ Hs and wind speed shows that Hs increases with wind speed in an approximately parabolic fashion (Fig. 6). To quantify the impact of sea state, wave energy at the Bragg wavelength was compared with coincident in situ $\mathrm{Hs}$ at each location (Fig. 5). For sea state 4 (1.25 $\leq \mathrm{Hs}<2.5 \mathrm{~m}$ ), wave energy increased rapidly as Hs increased. For sea states 5 and 6 $(\mathrm{Hs} \geq 2.5 \mathrm{~m})$, the wave energy increased slowly with $\mathrm{Hs}$; at lower sea state conditions (i.e., $\mathrm{Hs}<1.25 \mathrm{~m}$ ), wave energy increased even more slowly. Therefore, we were confident that sea state (i.e., sea state scale) could be used in the assessment below.

\section{b. Variation of data returns under different sea states}

To examine the relationship between the data returns of radar-derived radials and sea state, the conditional
TABLE 3. Vertical shear of the near-surface currents as shown by the RMSDs of the radial currents between the topmost bin of the ADCPs and bins 1-2 $\mathrm{m}$ deeper.

\begin{tabular}{cccc}
\hline \hline & Station & ADCP bins $(\mathrm{m})$ & RMSD $\left(\mathrm{m} \mathrm{s}^{-1}\right)$ \\
\hline $\mathrm{A}$ & DOSA & 1.5 vs 2.5 & 0.056 \\
& LOHI & 1.5 vs 2.5 & 0.071 \\
$\mathrm{~B}$ & DOSA & 1.5 vs 2.5 & 0.096 \\
& LOHI & 1.5 vs 2.5 & 0.069 \\
$\mathrm{C}$ & DOSA & 1.5 vs 2.5 & 0.045 \\
& LOHI & 1.5 vs 2.5 & 0.055 \\
$\mathrm{D}$ & DOSA & 1.5 vs 2.5 & 0.080 \\
& & 1.5 vs 3.5 & 0.096 \\
& LOHI & 1.5 vs 2.5 & 0.179 \\
& & 1.5 vs 3.5 & 0.217 \\
\hline
\end{tabular}

spatial coverage was computed as binned by the in situ Hs. In other words, if a certain sea state persisted for longer than $1 \mathrm{~h}$, the radar-derived radials during this period were considered in the calculation of spatial coverage. The best agreement between the radar-derived and ADCP-derived radials was obtained at station $\mathrm{C}$ located in the center of the detection area (Fig. 1). Therefore, in situ Hs measured at station $\mathrm{C}$ were used to analyze the variation of data returns under different sea states. The in situ Hs was in the range $0.28-5.25 \mathrm{~m}$ over the sample duration. The frequency of occurrence of sea states 2-6 at station $C$ is shown in Fig. 7. Sea state 3 was found to have the highest frequency of occurrence (31\%), followed by sea states 4 and 5 (each $28 \%$ ). Sea states 2 and 6 were found to have the lowest frequency of occurrence (each $6 \%$ ).

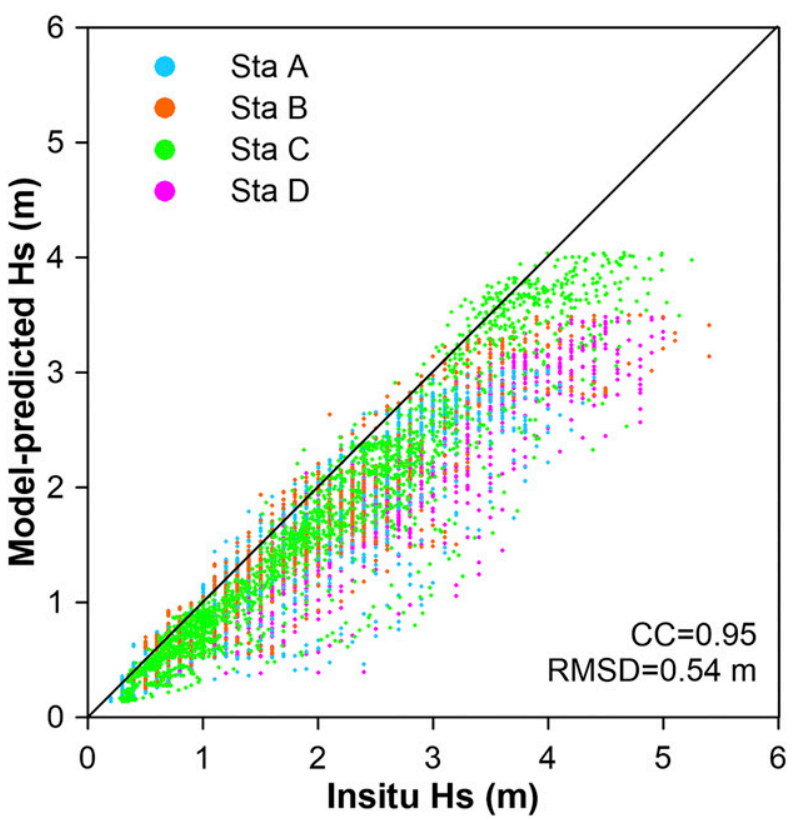

FIG. 4. Comparisons of Hs between model and buoys. 

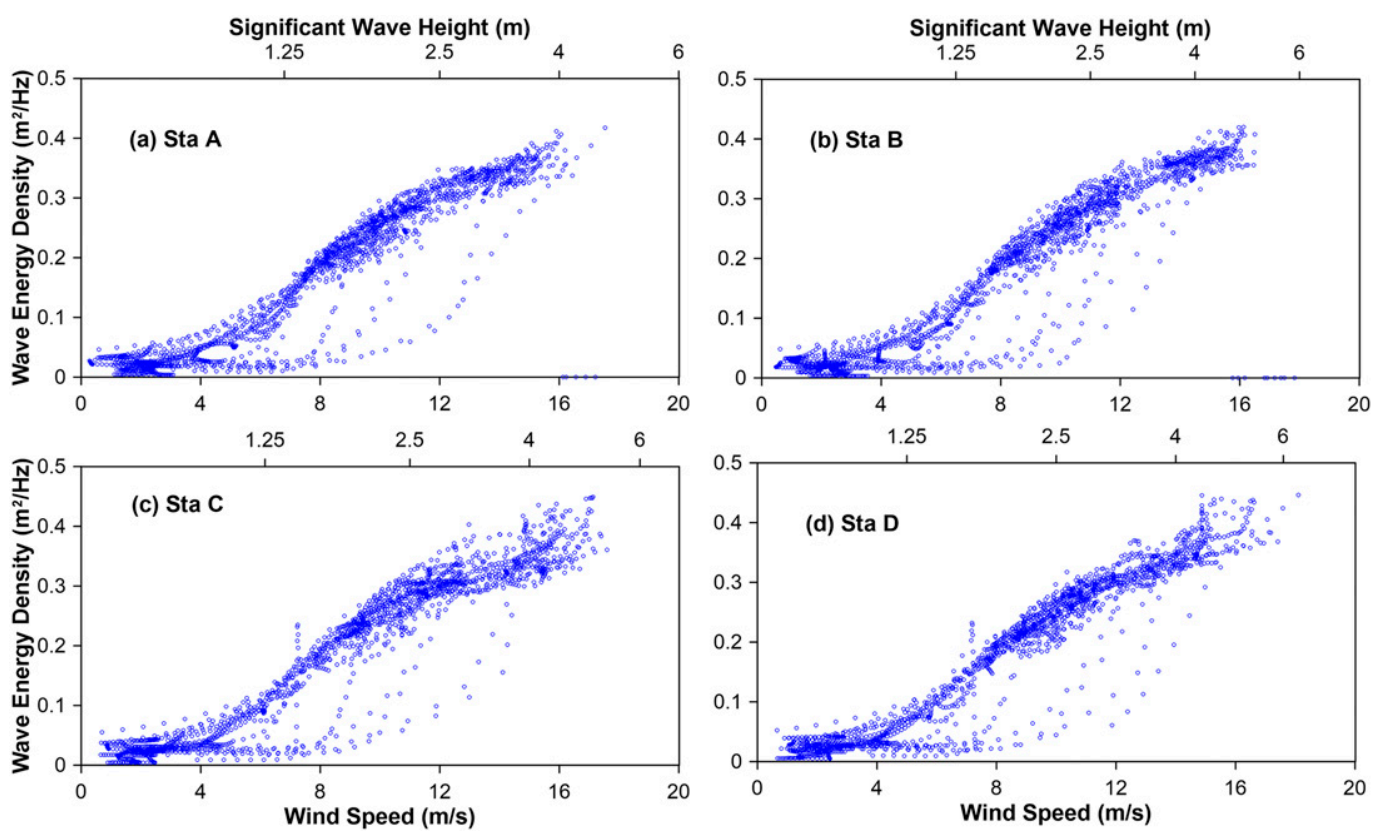

FIG. 5. Regression of local wind speed with wave energy density at $f=0.2865 \mathrm{~Hz}$ corresponding to Bragg waves for HF radar operated at $7.8 \mathrm{MHz}$.

The spatial coverage of radar-derived radials at sea states $2-6$ is presented in Fig. 8 (DOSA) and Fig. 9 (LOHI). The spatial coverage of radar-derived radials was found influenced by wave conditions. The distribution of spatial coverage (as shown in panels (a)-(e) of Figs. 8 and 9) showed that the highest spatial coverage was found at sea state 4 , while the lowest spatial coverage was found at sea state 2 . To simplify the comparison among the different sea states, panel (f) in both Figs. 8 and 9 displays the mean coverage as a function of range for measurements under different sea states. The value of the mean coverage at different sea states could be abbreviated as $\mathrm{COV}_{s}$, where subscript $s$ represents the sea state. At lower sea states, the mean coverage increased rapidly as the waves increased from sea state 2 to 4, especially for sample cells within the range 70 $200 \mathrm{~km}$. For sample cells within the range from 70 to $\sim 150 \mathrm{~km}$, as the range increased, the difference of mean coverage (at a certain range) between sea states 2 and 3 (i.e., $\mathrm{COV}_{3}-\mathrm{COV}_{2}$ ) increased rapidly. A similar result was found between sea states 3 and 4 . For sample cells within the range of $\sim 150-200 \mathrm{~km}$, as the range increased, the difference of mean coverage between two sea states (i.e., $\mathrm{COV}_{3}-\mathrm{COV}_{2}$ and $\mathrm{COV}_{4}-\mathrm{COV}_{3}$ ) decreased rapidly. At higher sea states, the mean coverage declined slowly as the waves increased from sea state 4 to 6 . However, as the range increased, the difference of mean coverage between two sea states (i.e., $\mathrm{COV}_{5}-\mathrm{COV}_{4}$ and $\left.\mathrm{COV}_{6}-\mathrm{COV}_{5}\right)$ increased, and this characteristic was more obvious for DOSA radials than for LOHI radials.

In summary, the results preliminarily demonstrated that the OSMAR071 (7.8-MHz) HF radar has best performance in terms of data returns at sea state 4 . For sea states $2-4$, the spatial coverage increased rapidly as

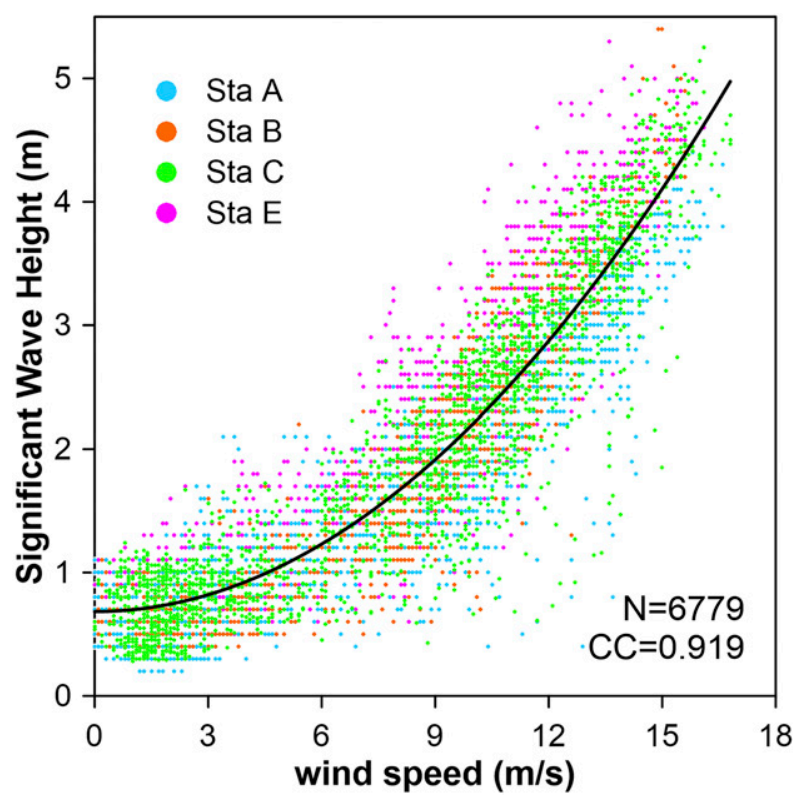

FIG. 6. Regression of in situ wind speed with Hs. 


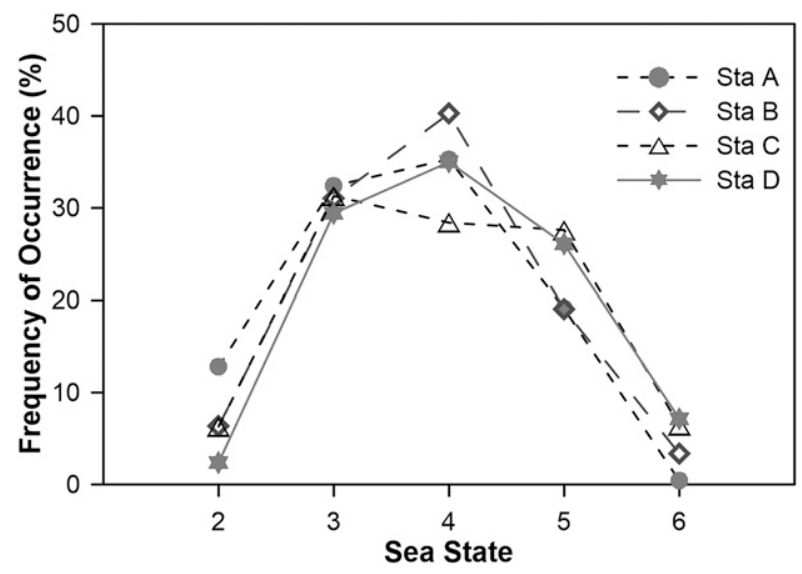

FIG. 7. Frequency of occurrence for sea states $2-6$ at the four locations.

the waves increased. For sea states $4-6$, as the waves increased, the spatial coverage decreased slightly.

\section{c. Comparison results of radials under different sea states}

To further examine the capability of an OSMAR071 radar in observing radials under different sea states, the conditional averages of the differences at sea states 2-6 were calculated based on in situ $\mathrm{Hs}$ measured at the same buoy as used for the ADCPs. The distribution of Hs for stations A, B, and D was found similar to that of station $\mathrm{C}$ (Fig. 7); that is, a lower frequency of occurrence was found at sea states 2 and 6 , while a higher frequency of occurrence was found at sea states 3-5. However, the highest frequency of occurrence was found at sea state $4(>35 \%)$ at stations A, B, and D.

Differences between radar-derived and ADCP-derived radials under different sea states are shown in Fig. 10 with comparison statistics (i.e., absolute values of MB, MAD, and RMSD) provided. As mentioned above, owing to short-term power interruption, no data were available at sea state 6 for LOHI radials at stations A and B. In consideration of the fewer data points at sea state 6 at station A (frequency of occurrence: $0.4 \%$; Fig. 7 ), the differences at that sea condition for the DOSA radials were removed.

With the best agreement between the radar-derived and ADCP-derived radials, the variation of the differences for sea states 2-6 at station $C$ were different from the other three locations. With slight underestimation or overestimation (MB from -0.05 to $0.03 \mathrm{~m} \mathrm{~s}^{-1}$ ), the differences (i.e., MAD and RMSD) tended to be relatively high when the sea surface was smooth and slight. At lower sea states (sea states 2-3), the MAD was 0.07$0.08 \mathrm{~m} \mathrm{~s}^{-1}$ and the RMSD was $0.09-0.11 \mathrm{~m} \mathrm{~s}^{-1}$ for the DOSA radials and the MAD was $0.09 \mathrm{~m} \mathrm{~s}^{-1}$ and the
RMSD was $0.11 \mathrm{~ms}^{-1}$ for the LOHI radials. When compared with lower sea states, the MAD and RMSD were reduced by $0.03-0.04 \mathrm{~m} \mathrm{~s}^{-1}$ at higher sea states (sea states 4-6); specifically, the differences were lowest at sea state 4 .

Except for the differences at station $\mathrm{C}$, the differences between the HF radar and ADCP radials increased as the waves increased. It was clear that the lowest MAD and RMSD were achieved at sea states 2 or 3 and that highest MAD and RMSD were achieved at sea states 5 or 6 . With bigger differences and obvious underestimation of radar-derived radials (MB was from -0.03 to $-0.31 \mathrm{~m} \mathrm{~s}^{-1}$ for sea states $2-6$ ), the differences at station $\mathrm{D}$ increased more rapidly than at other locations.

In addition, an assessment based on limited Hs was also carried out and compared with the above results, indicating pretty good consistency while $\mathrm{Hs}$ is available (mostly $<4 \mathrm{~m}$; results are shown in Fig. A1 in the appendix). However, the feature of the data trend could be better reflected by using sea state as a proxy.

The differences in the radar-ADCP comparisons tended to be relatively higher when the sea state was 2 and 3 at station $\mathrm{C}$, which exhibited the best agreement between the radar and ADCP radials. Conversely, the differences between the HF radar and ADCP radials increased as the waves increased at the other three locations. The results preliminarily demonstrated that as waves increased, radar-derived radials had different performance in different regions. In the following, several factors are considered to determine how the performance of radar-derived radials might vary in response to changing sea state conditions.

\section{Sources of measurement differences under different sea states}

\section{a. Energy loss and backscattering strength}

Some studies have evaluated the impact of sea state on data returns (or working range) based on different HF radar systems. Based on field experiments using a 27.65-MHz Wellen Radar (WERA) located in the North Sea, Gurgel et al. (1999) established that the working range decreases with increasing sea state. Similar experimental results were obtained by Cosoli et al. (2010), who observed a decrease in working range with increasing wind speed for three Coastal Ocean Dynamics Applications Radar (CODAR) systems (operating frequency: $24.5-35.9 \mathrm{MHz}$ ) located in the Adriatic Sea. Conversely, using a $5-\mathrm{MHz}$ CODAR on the West Florida shelf, Liu et al. (2010) found that radial coverage decreases as waves decrease $(\mathrm{Hs}<2 \mathrm{~m})$. Halverson et al. (2017) found the working range increases linearly with 

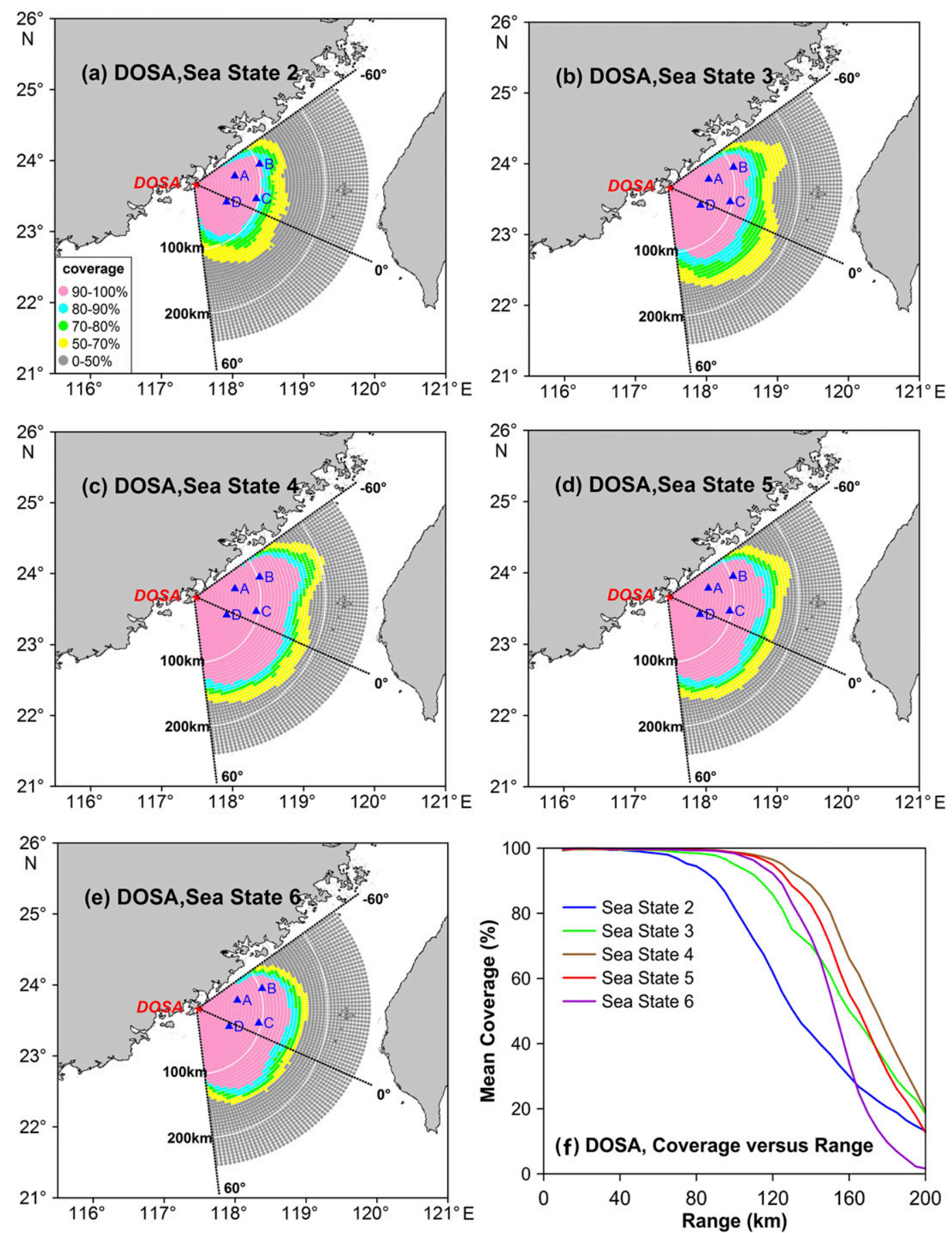

FIG. 8. Conditional spatial coverage of DOSA radar-derived radials at (a)-(e) sea states 2-6, respectively, as binned by in situ Hs at station D. (f) Mean coverage of sample cells at the same range vs range under different sea states.

wind speed at low wind speeds for a $25-\mathrm{MHz}$ CODAR in the southern Strait of Georgia. However, it was found to peak at a wind speed of $7.5 \mathrm{~m} \mathrm{~s}^{-1}(\mathrm{Hs} \approx 0.5 \mathrm{~m})$ and subsequently decrease at the highest speeds. The experimental results of the variation of data returns under different sea states in this study agreed qualitatively with the findings of both Liu et al. (2010) and Halverson et al. (2017). Also, they did not necessarily contradict the findings of both Gurgel et al. (1999) and Cosoli et al. (2010) because the particular critical wave height where 

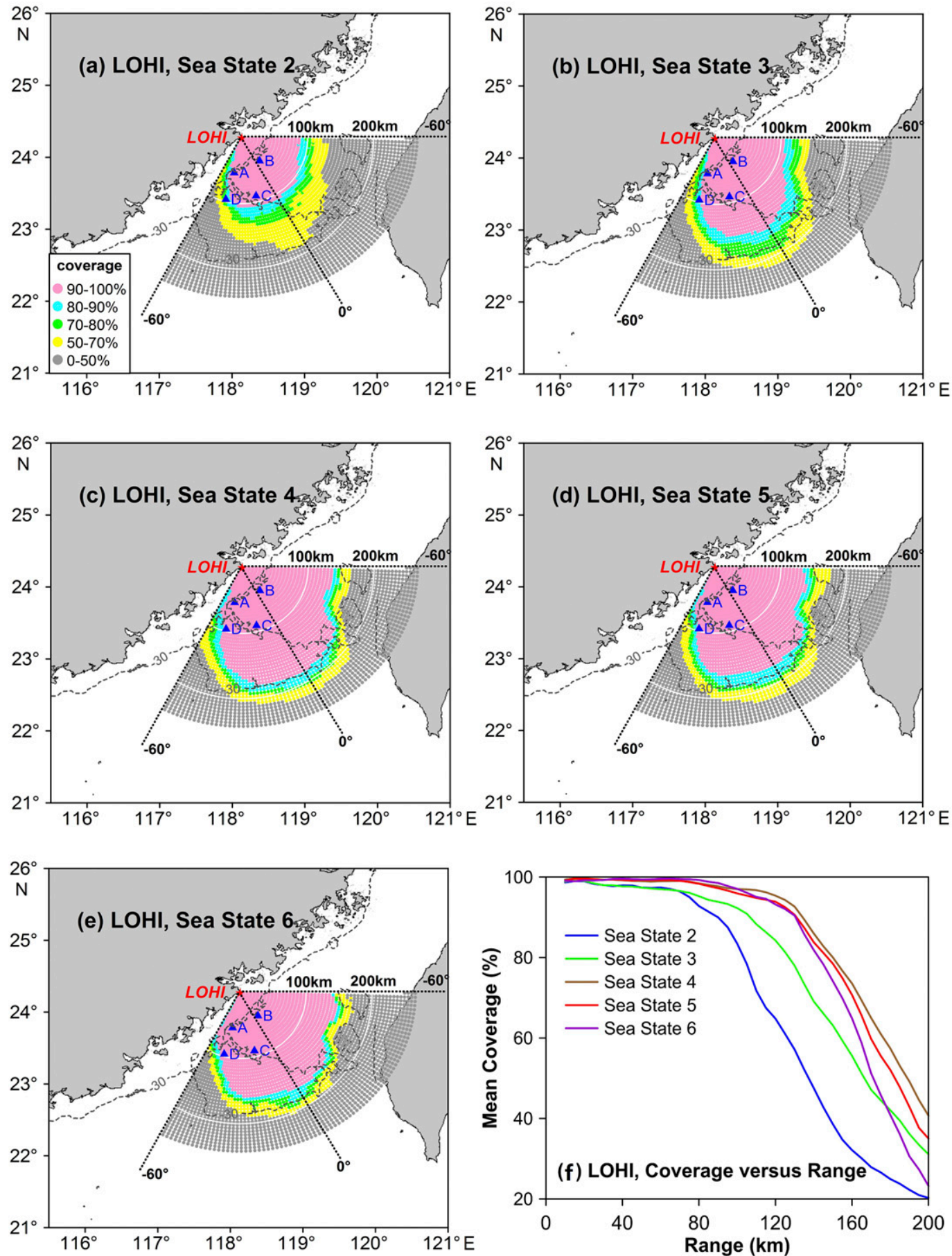

FIG. 9. As in Fig. 8, but for LOHI.

returned signal begins to decrease depends on the work frequency of radar. With higher work frequency, much lower critical wave height would be found in both Gurgel et al. (1999) and Cosoli et al. (2010).

The response of HF radar performance to sea state likely reflects the interplay of two factors, that is, energy loss and backscattering strength. Recently, Halverson et al. (2017) considered the interplay of these two factors based on a $25-\mathrm{MHz}$ CODAR in the southern Strait of Georgia, and suggested $16 \%$ of the variation of working range for radials is attributable to sea state. To determine the importance of these two competing factors on 

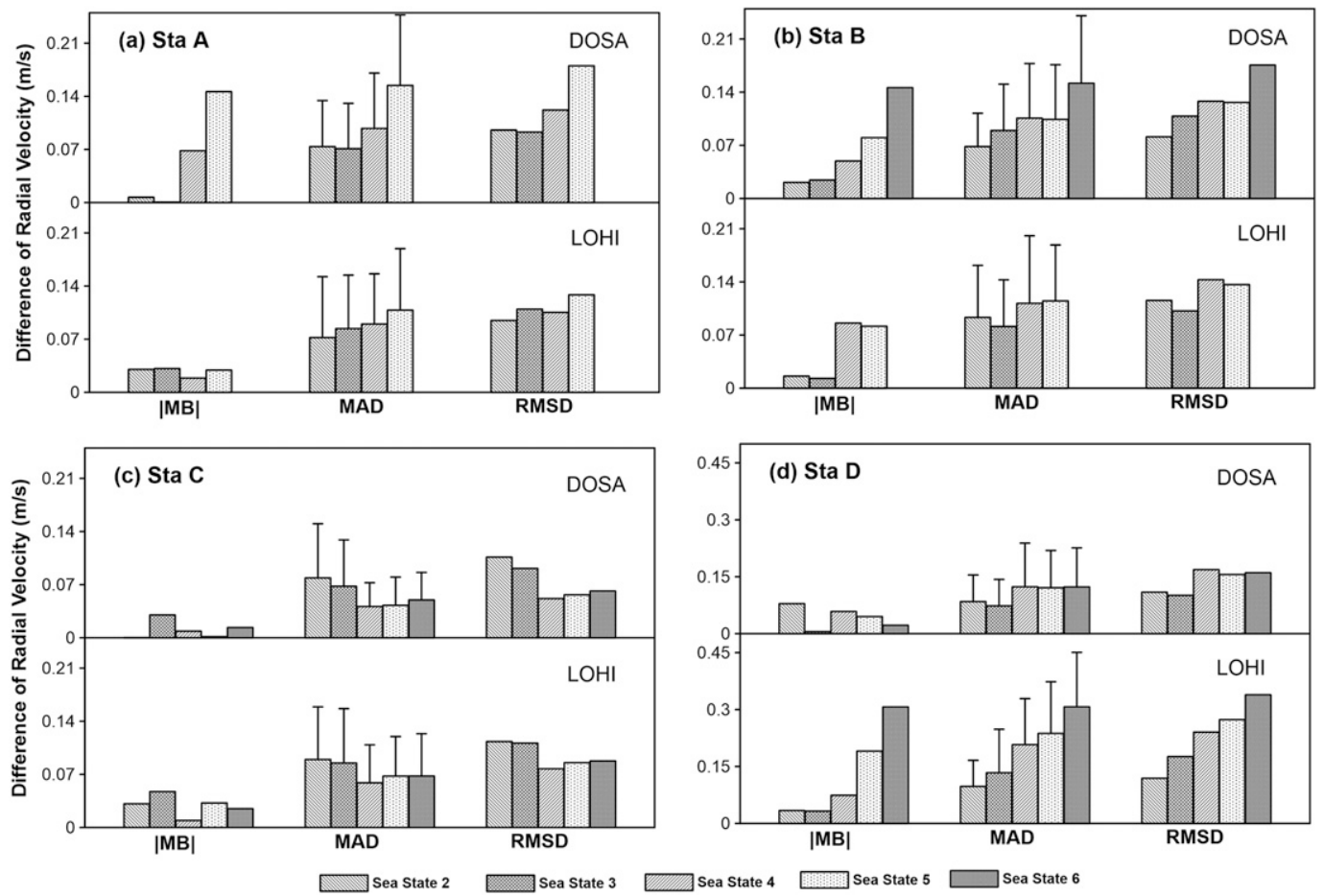

FIG. 10. Differences of radial currents between HF radars and ADCPs for sea states 2-6. Comparison statistics (i.e., absolute values of MB, MAD, and RMSD) are presented in each panel. Error bars represent standard deviation of the MAD at sea states 2-6.

the performance of radar-derived radials, we similarly examine how both the energy loss and the backscattering strength vary in the Taiwan Strait.

The first consideration is related to electromagnetic energy loss. The theoretical results of Barrick (1971) indicated that propagation loss generally increases with increasing sea state for HF ground waves. However, an increase in signal is observed at lower sea states at lower frequencies (e.g., for sea states 1-3 at 5 MHz; Fig. 6 in Barrick 1971). According to the theoretical results of Barrick (1971), energy loss is probably not pronounced at sea states $1-3$ for radar operating at $7.8 \mathrm{MHz}$ but increases rapidly at sea states $4-6$. The second consideration is related to backscattering strength. Waves influence the energy received by changing the scattering cross section (Barrick 1972, 1977). First-order scattering theory predicts that the scattering cross section is proportional to the wave energy of the Bragg wave. Hence, the backscattering strength increases as the wave energy at the Bragg wavelength increases. Based on analysis of the results presented in section 4a and Fig. 5, the backscattering strength should increase rapidly at sea state 4 , while it increases more slowly with Hs under lower (sea states 1 3) and higher (sea states 5-6) sea states.

Variations in the relative importance of backscattering strength and energy loss were evident in the data returns of radar-derived radials under different sea states. For sea states 2-3, analysis of both the energy loss and the backscattering strength indicated an increase in signal, which means the performance of the HF radars increased with sea state. The best performance of the HF radars at sea state 4 implies that the increase in backscattering strength must dominate over the increased energy loss. The relationship between in situ Hs and wind speed indicates that $\mathrm{Hs}$, which is a reasonable proxy for energy loss, increases with wind speed in an approximately parabolic fashion (Fig. 6). As the backscattering strength increased more slowly at sea states 5-6, energy loss is increasingly important in comparison with backscattering strength. Hence, the spatial coverage decreased slowly at sea states 5-6.

\section{b. Vertical variability}

To further examine the contribution of vertical variability under different sea states, the conditional averages of the differences at sea states 2-6 were calculated based on in situ Hs measured at the same buoy locations as used for the ADCPs. We calculated the RMSDs of the radials at the ADCP topmost bin $(1.5 \mathrm{~m})$ with bins $1 \mathrm{~m}$ deeper at each of the four locations.

The vertical shear under different sea states is shown in Fig. 11, together with the RMSDs. As Eulerian velocity 


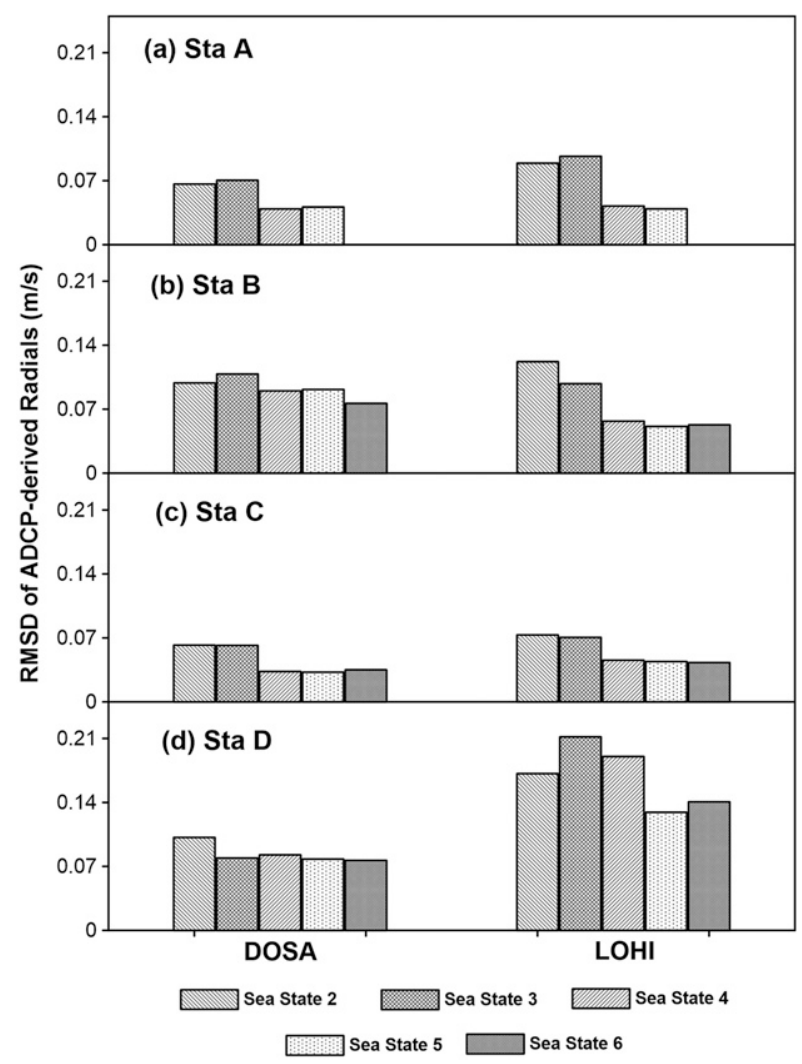

FIG. 11. Vertical shear of near-surface currents as shown by RMSD of the radial currents between the 1.5 - and $2.5-\mathrm{m}$ bins of ADCPs for sea states 2-6.

profiles become more uniform under higher sea states (Rascle et al. 2006), lower vertical shear is achieved at higher sea states (sea states 4-6), except for the vertical shear for the LOHI radials at station $\mathrm{D}$. The features of the trend of vertical shear and the differences of radarADCP comparisons under different sea states are similar at station $\mathrm{C}$ and are significantly different at stations $\mathrm{A}, \mathrm{B}$, and $\mathrm{D}$.

We note that these values of vertical shear might not represent the difference between the HF radar and ADCP radials, but could reflect the relative contribution of vertical shear. A rough estimation indicated that the contribution of vertical variability is nearly important under different sea states at station $\mathrm{C}$; that is, the ratio of the vertical shear to the RMSD of the radar-ADCP comparisons is within the range of $55 \%-65 \%$. However, for stations $\mathrm{A}$ and $\mathrm{B}$, the contribution of vertical variability is more significant under lower sea states (sea states 2-3), which might explain a substantial proportion (70\%-100\%) of the RMSD between the HF radar and ADCP radials. The magnitude of the contribution of vertical shear at sea states $2-3$ is almost double that at sea states $4-6$. These findings indicate that other factors are dominant in influencing the differences of radarADCP comparisons under higher sea states.

c. Stokes drift

\section{1) RELATIONSHIP BETWEEN RESIDUAL CURRENTS AND WINDS}

Sea surface currents are generated by tides, winds, and other factors-for example, geostrophic pressure gradients and density gradients. To assess the importance of wind in generating surface currents in the study area, analysis of the correlation between the wind and surface residual currents over the entire time series was conducted. Both the HF radar and ADCP current vectors were converted to hourly data. Based on harmonic tidal analysis performed using the MATLAB toolbox named T_Tide (Pawlowicz et al. 2002), residual currents were obtained from the vector currents of both the HF radars and ADCPs over the sample duration (38-45 days). Hourly averages of the wind vectors measured at the same locations as the currents were also derived for the same time steps as the current data.

Wind roses for the four locations over the sample duration (Fig. 12) showed that the wind blew predominantly from the northeast $\left(34^{\circ}-42^{\circ}\right)$. The wind direction was almost aligned with the Taiwan Strait (Fig. 1). Both the winds and the residual currents were projected in directions parallel $\left(U: 45^{\circ}\right.$ and $225^{\circ}$ north) and perpendicular ( $V: 135^{\circ}$ and $315^{\circ}$ north) to the Taiwan Strait, with the direction of positive values of $U$ to the southwest and of $V$ to the southeast.

The $U$ and $V$ components of both the residual current velocity and the wind speed were inspected. As shown in panels a and b of Figs. 13-16, the time series of the $U$ components of the residual current velocity exhibit reasonable consistency with wind speed at the four locations with reasonably strong correlation (CC: $0.8-0.9)$. However, with $92 \%$ of the wind speeds in the range from -4 to $4 \mathrm{~m} \mathrm{~s}^{-1}$, the $\mathrm{V}$ components showed weaker correlation (CC: $0.06-0.45)$. The results indicated that wind has an important role in the surface current dynamics in the direction parallel to the Taiwan Strait. The results were consistent with previous findings of Lai et al. (2017), who projected the residual current of $\mathrm{HF}$ radar into the dominant wind direction (around $37^{\circ} \mathrm{N}$ ) and found the projected components in this direction showed a reasonably high CC of 0.827 .

\section{2) COMPARISON OF RESIDUAL CURRENT DIFFERENCES AND WINDS}

Comparisons of residual current differences (OSMAR071 - ADCP) and winds are shown in panel c of Figs. 13-16. Winds were weak in the direction 

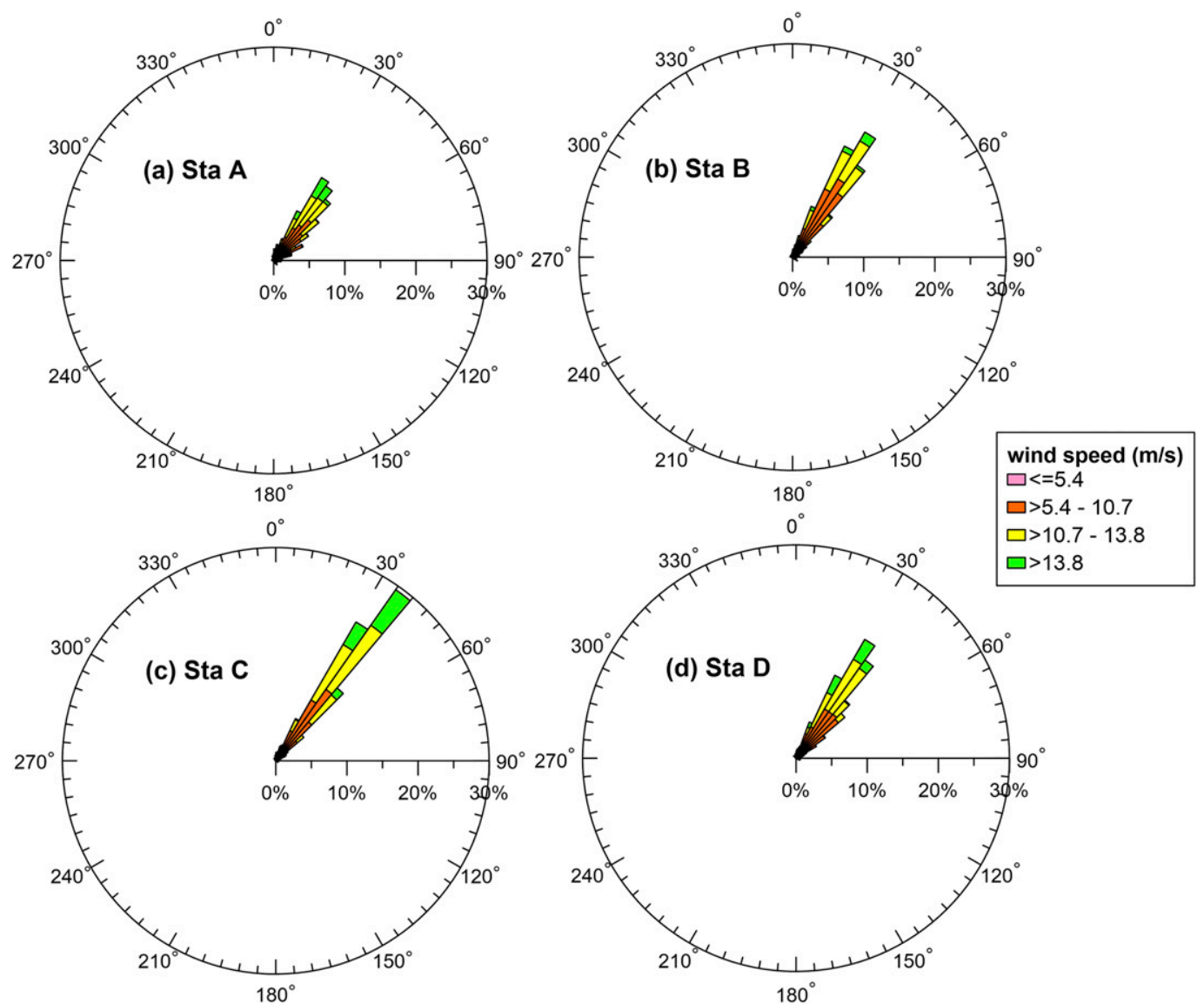

FIG. 12. Rose plots of wind direction at the four buoy locations. The color scale indicates corresponding wind speed. Radius axis designates the frequency of occurrence of the winds.

perpendicular to the Taiwan Strait and therefore their effect was probably negligible relative to the uncertainty in the radar measurements; hence, only $U$ components are analyzed here. Although the scatter of differences is relatively large, the difference appeared to explain the general trend. The larger scatter was probably introduced by instrument noise, collocation and concurrence differences, and by geophysical processes such as the Ekman drift current and the Stokes drift current (Graber et al. 1997; Liu et al. 2010). Larger scatter was also found in previous comparisons of surface current differences and wind (Laws 2001; Ullman et al. 2006).

Except for station $\mathrm{C}$, the differences of $U_{\text {osmar }}(U$ component of OSMAR071) minus $U_{\mathrm{ADCP}}(U$ component of ADCP) were correlated (CC: $0.42-0.69)$ with $U_{\text {wind }}(U$ component of wind), indicating a tendency for larger differences to be associated with higher wind speeds. When compared with stations $\mathrm{A}, \mathrm{B}$, and $\mathrm{D}$, the relationship between $U_{\text {osmar }}-U_{\mathrm{ADCP}}$ and $U_{\text {wind }}$ at station $\mathrm{C}$ was significantly different, that is, weakly correlated (CC: 0.25), which showed that differences decreased slightly as wind speed increased.

\section{3) CONTRibution OF STOKes DRIFT TO RADAR-DERIVED CURRENTS}

Assuming that the phases of the wave components are uncorrelated, Stokes drift is usually estimated from the wave spectrum (Kenyon 1969; Rascle et al. 2006; Chavanne 2018, and references therein). Some earlier studies used the relationship between Stokes drift and wind speed to estimate the magnitude of Stokes drift (Rascle et al. 2006, 2008; Mao and Heron 2008; Ardhuin et al. 2009).

To determine the existence and extent of the contribution of Stokes drift to the HF radar current measurements, we examine the relationship between wind speed and the residual current differences of the HF radar and ADCPs. The slopes of the linear fit to the residual current differences plotted as a function of wind speed are shown in panel c of Figs. 13-16, from which the following can be ascertained: (i) when compared with 

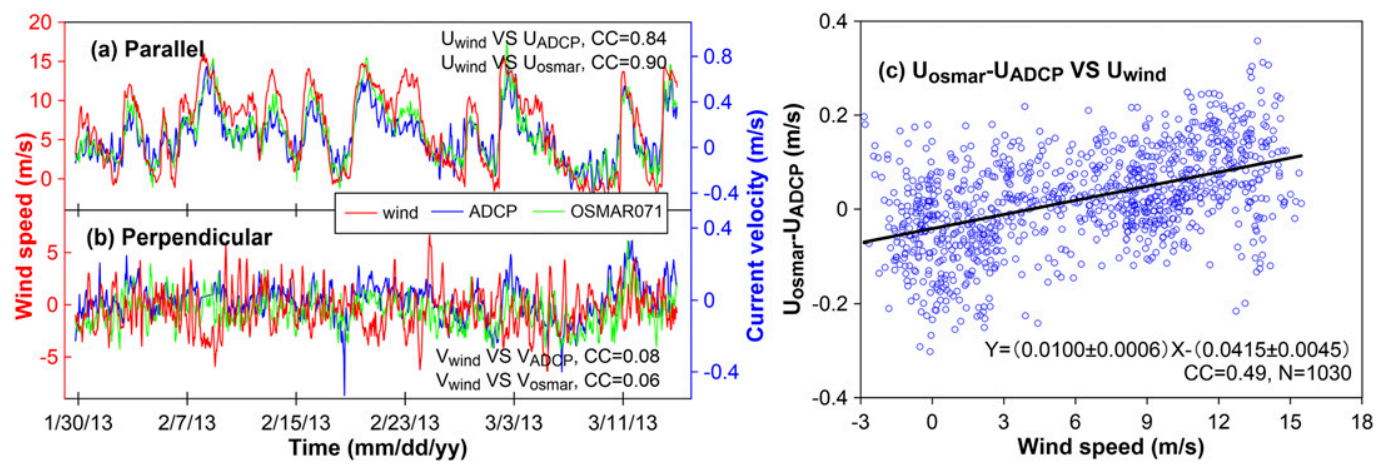

FIG. 13. The $U$ and $V$ components of residual current and wind speed at station A: (a) $U$ component (parallel to the Taiwan Strait) of the residual current vs that of the wind, (b) $V$ component (perpendicular to the Taiwan Strait) of the residual current vs that of the wind, and (c) differences for $U$ components of the residual current (i.e., $U_{\text {osmar }}$ - $\left.U_{\mathrm{ADCP}}\right)$ vs the wind $\left(U_{\text {wind }}\right)$. Correlation coefficients are shown in the top-right and bottom-right corners of (a) and (b), respectively. A linear best fit to the data (solid line) along with the regression equation and correlation coefficient of the linear fit to the data is included in (c). The $U_{\text {osmar }}$ and $V_{\text {osmar }}$ represent the $U$ and $V$ components for the residual current of the OSMAR071 HF radar, $U_{\mathrm{ADCP}}$ and $V_{\mathrm{ADCP}}$ represent those of the ADCP, and $U_{\text {wind }}$ and $V_{\text {wind }}$ represent those of the wind.

the topmost bin of the ADCPs $(1.5 \mathrm{~m}$, same as the effective depth of the radar measurements), the slope was $0.0100 \pm 0.0006$ and $0.0077 \pm 0.0006$ at stations $\mathrm{A}$ and $\mathrm{B}$, respectively; (ii) when compared with the $3.5-\mathrm{m}$ bin of the ADCPs, the slope at station D was obvious larger $(0.0182 \pm 0.0007)$ than at stations A and B; and (iii) with slope of $-0.0037 \pm 0.0004$, the differences decreased slightly as the wind speed increased at station C.

The response of the surface current to wind comprises both the Stokes drift and the Ekman drift currents. As suggested by previous findings, an ADCP measures the Eulerian current (Röhrs et al. 2015). Currents derived by HF radar and ADCPs differ by the extent to which Stokes drift might be included and by the Ekman drift, which depends on the sampling depth. With almost equivalent effective depths for the radar and ADCP measurements, the slope values of stations A and B reflect the relative contribution of Stokes drift to the radar-derived current. The slope values were found comparable with the results summarized in Fig. 2 of Chavanne (2018), which confirmed that Stokes drift was included in the HF radar current measurements.

In general, $\mathrm{HF}$ radars should measure a quantity related to Stokes drift in addition to the mean Eulerian currents. However, the slope value of station Cindicated that the influence of Stokes drift was insignificant. This was probably because of the large angles (angles of approximately $60^{\circ}-66^{\circ}$ ) between the direction of the HF radar radials and the predominant wind direction, which meant that the influence of Stokes drift was probably less significant than the contribution of vertical shear in the radar measurements.

\section{d. Sand waves on the Taiwan Banks}

Based on the above comparisons, it was found that (i) the comparatively lower correlation and bigger
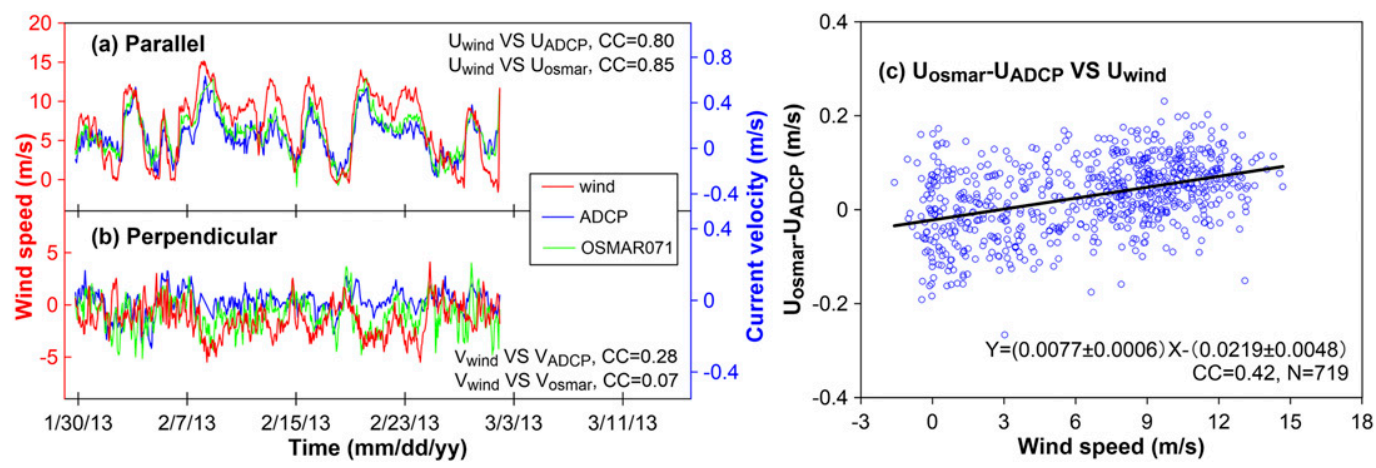

FIG. 14. As in Fig. 13, but for station B. 

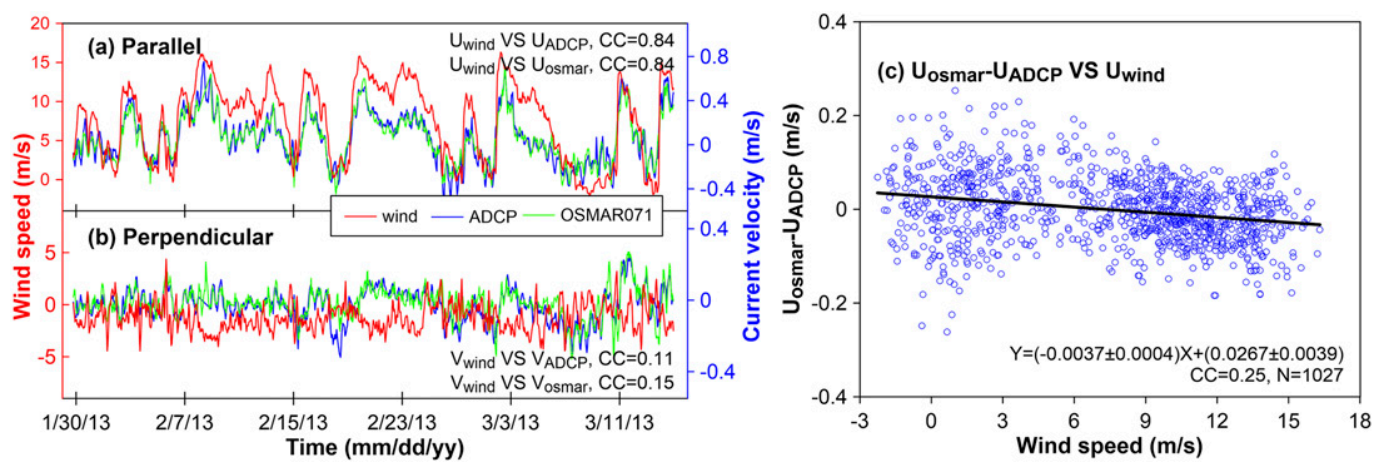

FIG. 15. As in Fig. 13, but for station C.

difference (Fig. 2) and (ii) the larger slope of the linear fit to $U_{\text {osmar }}-U_{\mathrm{ADCP}}$ and $U_{\text {wind }}$ at station D (Fig. 16c) were probably influenced by the shallow waters and submarine sand waves of the TB. The first consideration is related to the greater wave steepness. This could be explained by two different mechanisms. The first, based on the weak hydrodynamic interaction theory of surface short waves with currents, suggests sea surface short waves are gradually modulated by the corrugated submarine topography (Shao et al. 2011). The second, based on theoretical and experimental results for the TB, Zhang et al. (2012) suggested that band gap and wave localization become important physical mechanisms when sea surface waves propagate through natural large-scale sand waves. In this study, radar sea echoes and nonlinear effects were enhanced by the greater wave steepness in the TB. Other experimental results using HF radar to map wave height generally confirm this argument (Cai et al. 2019). The second consideration is related to the spatial inhomogeneity of currents (Figs. 2, 3). First, the sampling domain of the HF radar was different from that of the ADCP. The spatial inhomogeneity will further accentuate these differences between sensors. Second, the differences between the HF radar and the ADCP will differ because of differences in the geophysical processes resulting from horizontal inhomogeneity and vertical shear (Graber et al. 1997).

\section{Summary}

To observe surface currents in the southwestern Taiwan Strait, two OSMAR071 (7.8-MHz) HF radars and four moored ADCPs were operated concurrently during January-March 2013. Based on ADCP-recorded currents, an evaluation of performance was conducted to assess the utility of HF radar in mapping surface currents under different sea states.

Comparison of radar and ADCP radials showed the MB was -0.01 to $0.07 \mathrm{~m} \mathrm{~s}^{-1}$, MAD was $0.05-0.10 \mathrm{~m} \mathrm{~s}^{-1}$, and RMSD was $0.07-0.13 \mathrm{~m} \mathrm{~s}^{-1}$ (except for station D). These differences are comparable to the findings of previous studies. However, bigger differences were found at station D (RMSD for DOSA and LOHI radials was 0.15 and $0.24 \mathrm{~m} \mathrm{~s}^{-1}$, respectively) located in a sand waves dominated shallow area.

To provide greater insight into the geophysical processes involved, the performance of the HF radar was further evaluated under different sea states. Both the data returns for radar-derived radials and the differences between the radar and ADCP radials were found
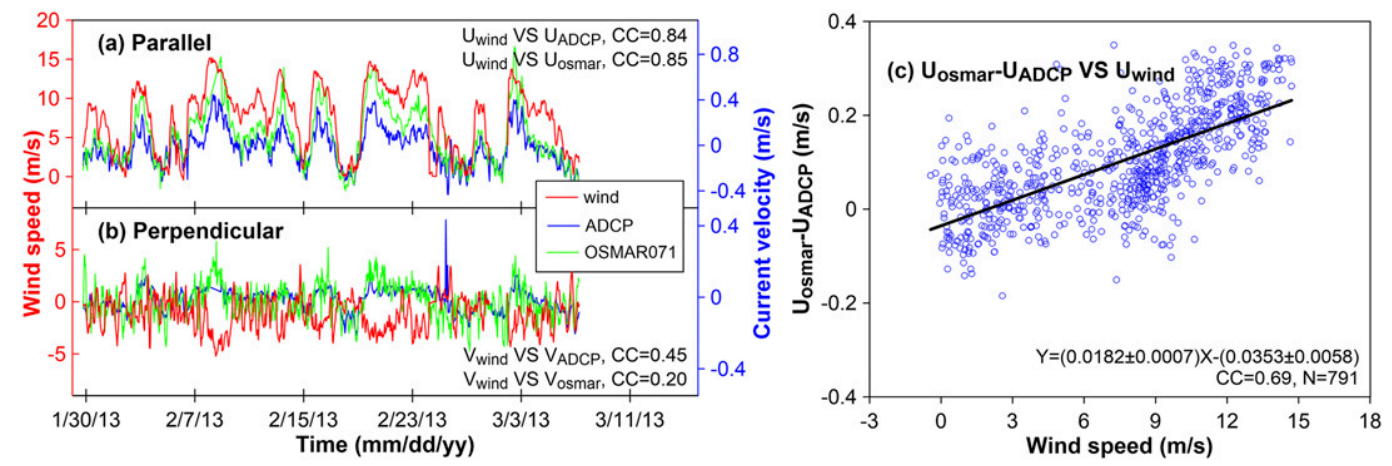

FIG. 16. As in Fig. 13, but for station D. 

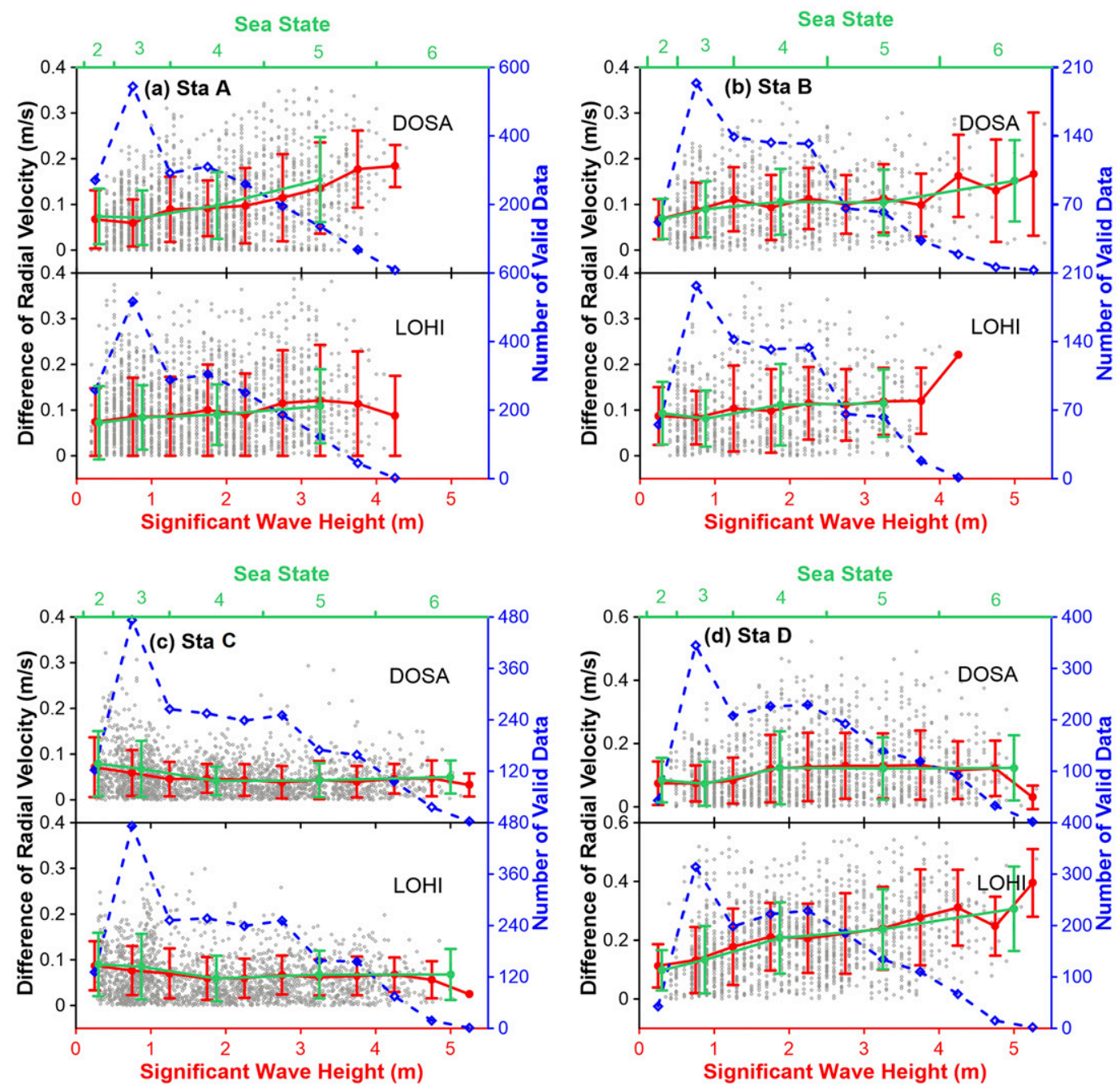

Absolute difference

$\multimap-$ MAD for Hs in $0.5-\mathrm{m}$ bins
$-\diamond$ Number of valid data for $\mathrm{Hs}$ in $0.5-\mathrm{m}$ bins

FIG. A1. Differences of radial currents between HF radars and ADCPs. The green curve is the MAD between the radar and ADCP radials with reference to sea state (cited from Fig. 10), and the red curve is the MAD vs Hs in 0.5-m bins; gray dots are the absolute difference between the radar and ADCP radials, error bars represent standard deviation of the MAD, and the blue curve shows the number of valid data.

to vary with sea state. First, the HF radar had best performance in terms of data returns at sea state 4 . For sea states $2-4$, the spatial coverage increased rapidly as the waves increased. For sea states $4-6$, as the waves increased, the spatial coverage decreased slowly. Second, the differences of radar-ADCP comparisons tended to be relatively high when the sea state was smooth and slight at station $\mathrm{C}$, which had the best agreement between the radar and ADCP radials. However, the differences between the radar and ADCP radials increased as the waves increased at the other three locations.

Based on the evaluation results of the HF radar under different sea states, it was supposed that the inhomogeneity velocity profile has significant influence on the differences between the HF radar and ADCP current measurements, especially under lower sea states (sea states 2-3). Comparison results also confirmed that Stokes drift was included in the HF radar current measurements. However, a definitive answer to the question whether the influence of Stokes drift is significant relative to the uncertainty in radar measurements would probably depend on wind speed and direction.

Acknowledgments. This work was funded by two grants from the National Key Research and Development Project of China (2017YFC1404801 and 2016YFC1401104) and the 
Innovative Development Demonstration Project of Marine Economy in Fuzhou (FZHJ16). We thank the China Precise Ocean Detection Technology Co., Ltd., for providing radar and in situ data. We thank James Buxton, M.Sc., from Liwen Bianji, Edanz Group China (www.liwenbianji.cn./ ac), for editing the English text of this paper.

\section{APPENDIX}

\section{Differences of Radial Currents}

Figure A1 shows the results of an examination of differences of radial currents between HF radars and ADCPs between HF radars and ADCPs with reference to sea state and Hs in $0.5-\mathrm{m}$ bins.

\section{REFERENCES}

Abascal, A. J., S. Castanedo, R. Medina, I. J. Losada, and E. Alvarez-Fanjul, 2009: Application of HF radar currents to oil spill modelling. Mar. Pollut. Bull., 58, 238-248, https:// doi.org/10.1016/j.marpolbul.2008.09.020.

Ardhuin, F., L. Marié, N. Rascle, P. Forget, and A. Roland, 2009: Observation and estimation of Lagrangian, Stokes, and Eulerian currents induced by wind and waves at the sea surface. J. Phys. Oceanogr., 39, 2820-2838, https://doi.org/ 10.1175/2009JPO4169.1.

Barrick, D. E., 1971: Theory of HF and VHF propagation across the rough sea, 2, application to HF and VHF propagation above the sea. Radio Sci., 6, 527-533, https://doi.org/10.1029/ RS006i005p00527.

_ 1972: Remote sensing of sea-state by radar. Remote Sensing of the Troposphere, V. E. Derr, Ed., NOAA, 12-31.

- 1977: Extraction of wave parameters from measured HF radar sea-echo Doppler spectra. Radio Sci., 12, 415-424, https://doi.org/10.1029/RS012i003p00415.

_ , and B. L. Weber, 1977: On the nonlinear theory for gravity waves on the ocean's surface. Part II: Interpretation and applications. J. Phys. Oceanogr., 7, 11-21, https://doi.org/10.1175/ 1520-0485(1977)007<0011:OTNTFG > 2.0.CO;2.

_ , and B. J. Lipa, 1999: Radar angle determination with MUSIC direction finding. U.S. Patent 5990834,12 pp., http:// www.codar.com/images/about/patents/05990834.PDF.

_ M. W. Evans, and B. L. Weber, 1977: Ocean surface currents mapped by radar. Science, 198, 138-144, https://doi.org/10.1126/ science.198.4313.138.

Booij, N., R. C. Ris, and L. H. Holthuijsen, 1999: A thirdgeneration wave model for coastal regions: 1 . Model description and validation. J. Geophys. Res., 104, 7649-7666, https:// doi.org/10.1029/98JC02622.

Breivik, Ø., and Ø. Sætra, 2001: Real time assimilation of HF radar currents into a coastal ocean model. J. Mar. Syst., 28, 161-182, https://doi.org/10.1016/S0924-7963(01)00002-1.

- , A. A. Allen, C. Maisondieu, and M. Olagnon, 2013: Advances in search and rescue at sea. Ocean Dyn., 63, 83-88, https://doi.org/10.1007/s10236-012-0581-1.

Cai, L., and Coauthors, 2019: Assessment of significant wave height in the Taiwan Strait measured by a single HF radar system. J. Atmos. Oceanic Technol., 36, 1419-1432, https://doi.org/ 10.1175/JTECH-D-18-0146.1.
Chavanne, C., 2018: Do high-frequency radars measure the waveinduced Stokes drift. J. Atmos. Oceanic Technol., 35, 10231031, https://doi.org/10.1175/JTECH-D-17-0099.1.

Cosoli, S., A. Mazzoldi, and M. Gačić, 2010: Validation of surface current measurements in the northern Adriatic Sea from highfrequency radars. J. Atmos. Oceanic Technol., 27, 908-919, https://doi.org/10.1175/2009JTECHO680.1.

Crombie, D. D., 1955: Doppler spectrum of sea echo at $13.56 \mathrm{Mc} . / \mathrm{s}$. Nature, 175, 681-682, https://doi.org/10.1038/175681a0.

Dai, H., S. Shang, Z. He, and K. Liu, 2016: Analysis and compensation of ADCP current direction error caused by ambient magnetic field. Flow Meas. Instrum., 52, 115-120, https:// doi.org/10.1016/j.flowmeasinst.2016.09.013.

Emery, B. M., L. Washburn, and J. Harlan, 2004: Evaluating radial current measurements from CODAR high-frequency radars with moored current meters. J. Atmos. Oceanic Technol., 21, 1259-1271, https://doi.org/10.1175/1520-0426(2004)021<1259: ERCMFC $>2.0 . \mathrm{CO} ; 2$.

Essen, H. H., and K. W. Gurgel, 2000: On the accuracy of current measurements by means of HF radar. IEEE J. Oceanic Eng., 25, 472-480, https://doi.org/10.1109/48.895354.

Graber, H. C., B. K. Haus, R. D. Chapman, and L. K. Shay, 1997: HF radar comparisons with moored estimates of current speed and direction: Expected differences and implications. J. Geophys. Res., 102, 18749-18 766, https://doi.org/10.1029/97JC01190.

Guo, T. T., W. Y. Gao, Y. Gao, and F. Gong, 2010: An analysis of the climate characteristics for Taiwan Strait (in Chinese). Mar. Forecasts, 27, 53-58, https://doi.org/10.11737/j.issn.1003-0239.2010.01.010.

Gurgel, K.-W., H.-H. Essen, and S. Kingsley, 1999: Highfrequency radars: Physical limitations and recent developments. Coastal Eng., 37, 201-218, https://doi.org/10.1016/ S0378-3839(99)00026-5.

Halverson, M., R. Pawlowicz, and C. Chavanne, 2017: Dependence of $25-\mathrm{MHz} \mathrm{HF}$ radar working range on near-surface conductivity, sea state, and tides. J. Atmos. Oceanic Technol., 34, 447-462, https://doi.org/10.1175/JTECH-D-16-0139.1.

Hammond, T. M., C. Pattiaratchi, D. Eccles, M. Osborne, L. Nash, and M. Collins, 1987: Ocean Surface Current Radar (OSCR) vector measurements on the inner continental shelf. Cont. Shelf Res., 7, 411-431, https://doi.org/10.1016/0278-4343(87) 90108-7.

Hasselmann, K., 1971: Determination of ocean wave spectra from Doppler radio return from the sea surface. Nature Phys. Sci., 229, 16-17, https://doi.org/10.1038/PHYSCI229016A0.

Hou, J., and Coauthors, 1997: Remote sensing of ocean surface currents by HF radar (in Chinese). Chin. J. Geophys., 40, 18-26.

Kenyon, K. E., 1969: Stokes drift for random gravity waves. J. Geophys. Res., 74, 6991-6994, https://doi.org/10.1029/ JC074i028p06991.

Kohut, J. T., H. J. Roarty, and S. M. Glenn, 2006: Characterizing observed environmental variability with HF Doppler radar surface current mappers and acoustic Doppler current profilers: Environmental variability in the coastal ocean. IEEE J. Oceanic Eng., 31, 876-884, https://doi.org/10.1109/JOE.2006.886095. _- E. Randall-Goodwin, S. Glenn, and C. S. Lichtenwalner, 2012: Evaluation of two algorithms for a network of coastal HF radars in the Mid-Atlantic Bight. Ocean Dyn., 62, 953-968, https://doi.org/10.1007/s10236-012-0533-9.

Kundu, P. K., 1976: Ekman veering observed near the ocean bottom. J. Phys. Oceanogr., 6, 238-242, https://doi.org/10.1175/ 1520-0485(1976)006<0238:EVONTO > 2.0.CO;2.

Lai, Y., H. Zhou, and B. Wen, 2017: Surface current characteristics in the Taiwan Strait observed by high-frequency radars. 
IEEE J. Oceanic Eng., 42, 449-457, https://doi.org/10.1109/ JOE.2016.2572818.

,$- \ldots$, Y. Zeng, and B. Wen, 2018: Accuracy assessment of surface current velocities observed by OSMAR-S high-frequency radar system. IEEE J. Oceanic Eng., 43, 1068-1074, https://doi.org/10.1109/JOE.2017.2769179.

Laws, K., 2001: Measurements of near surface ocean currents using HF radar. Ph.D. thesis, University of California, 171 pp.

Liu, L., X. B. Wu, F. Cheng, S. L. Yang, and H. Y. Ke, 2007: Algorithm for $\mathrm{HF}$ radar vector current measurements. J. Oceanogr., 63, 47-66, https://doi.org/10.1007/s10872-007-0005-x.

Liu, Y. G., R. H. Weisberg, C. R. Merz, S. Lichtenwalner, and G. J. Kirkpatrick, 2010: HF radar performance in a low-energy environment: CODAR SeaSonde experience on the West Florida shelf. J. Atmos. Oceanic Technol., 27, 1689-1710, https://doi.org/10.1175/2010JTECHO720.1.

,-- , and - , 2014: Assessment of CODAR SeaSonde and WERA HF radars in mapping surface currents on the West Florida shelf. J. Atmos. Oceanic Technol., 31, 1363-1382, https://doi.org/10.1175/JTECH-D-13-00107.1.

Mao, Y., and M. L. Heron, 2008: The influence of fetch on the response of surface currents to wind studied by HF ocean surface radar. J. Phys. Oceanogr., 38, 1107-1121, https:// doi.org/10.1175/2007JPO3709.1.

Ohlmann, C., P. White, L. Washburn, E. Terrill, B. Emery, and M. Otero, 2007: Interpretation of coastal HF radar derived surface currents with high-resolution drifter data. J. Atmos. Oceanic Technol., 24, 666-680, https://doi.org/10.1175/JTECH1998.1.

Paduan, J. D., and L. K. Rosenfeld, 1996: Remotely sensed surface currents in Monterey Bay from shore-based HF radar (coastal ocean dynamics application radar). J. Geophys. Res., 101, 20 669-20 686, https://doi.org/10.1029/96JC01663.

_ of ocean surface currents. Annu. Rev. Mar. Sci., 5, 115-136, https://doi.org/10.1146/annurev-marine-121211-172315.

—, K. C. Kim, M. S. Cook, and F. P. Chavez, 2006: Calibration and validation of direction-finding high-frequency radar ocean surface current observations. IEEE J. Oceanic Eng., 31, 862875, https://doi.org/10.1109/JOE.2006.886195.

Pawlowicz, R., B. Beardsley, and S. Lentz, 2002: Classical tidal harmonic analysis including error estimates in MATLAB using T_TIDE. Comput. Geosci., 28, 929-937, https://doi.org/ 10.1016/S0098-3004(02)00013-4.

Rascle, N., F. Ardhuin, and E. A. Terray, 2006: Drift and mixing under the ocean surface. A coherent one-dimensional description with application to unstratified conditions. J. Geophys. Res., 111, C03016, https://doi.org/10.1029/2005JC003004.

, ——, P. Queffeulou, and D. Croizé-Fillon, 2008: A global wave parameter database for geophysical applications. Part I: Wave-current-turbulence interaction parameters for the open ocean based on traditional parameterizations. Ocean Modell., 25, 154-171, https://doi.org/10.1016/ j.ocemod.2008.07.006.
Röhrs, J., A. K. Sperrevik, K. H. Christensen, G. Broström, and Ø. Breivik, 2015: Comparison of HF radar measurements with Eulerian and Lagrangian surface currents. Ocean Dyn., 65, 679-690, https://doi.org/10.1007/s10236-015-0828-8.

Schmidt, R. O., 1986: Multiple emitter location and signal parameters estimation. IEEE Trans. Antennas Propag., 34, 276-280, https://doi.org/10.1109/TAP.1986.1143830.

Schule, J. J., 1966:Sea state. The Encyclopedia of Oceanography, R. W. Fairbridge, Ed., Reinhold Publishing, 786-792.

Shao, H., Y. Li, and L. Li, 2011: Sun glitter imaging of submarine sand waves on the Taiwan banks: Determination of the relaxation rate of short waves. J. Geophys. Res., 116, C06024, https://doi.org/10.1029/2010JC006798.

Shay, L. K., T. M. Cook, H. Peters, A. J. Mariano, P. E. An, A. Soloviev, R. Weisberg, and M. Luther, 2002: Very high frequency radar mapping of surface currents. IEEE J. Oceanic Eng., 27, 155-169, https://doi.org/10.1109/JOE.2002.1002470.

Shen, W., K.-W. Gurgel, G. Voulgaris, T. Schlick, and D. Stammer, 2012: Wind-speed inversion from HF radar first-order backscatter signal. Ocean Dyn., 62, 105-121, https://doi.org/10.1007/ s10236-011-0465-9.

Stewart, R. H., and J. W. Joy, 1974: HF radio measurements of surface currents. Deep-Sea Res., 21, 1039-1049, https://doi.org/ 10.1016/0011-7471(74)90066-7.

Ullman, D. S., J. O'Donnell, J. Kohut, T. Fake, and A. Allen, 2006: Trajectory prediction using HF radar surface currents: Monte Carlo simulations of prediction uncertainties. J. Geophys. Res., 111, C12005, https://doi.org/10.1029/2006JC003715.

Wu, S., Z. Yang, B. Wen, Z. Shi, J. Tian, H. Gao, X. Wu, and H. Ke, 2001: Test of HF ground wave radar OSMAR2000 at the eastern China Sea. OCEANS 2001, Honolulu, HI, IEEE, 646648, https://doi.org/10.1109/OCEANS.2001.968799.

Wu, X. B., L. Li, Y. Shao, Y. Li, and T. Guo, 2009: Experimental determination of significant waveheight by OSMAR071: Comparison with results from buoy. Wuhan Univ. J. Nat. Sci., 14, 499-504, https://doi.org/10.1007/s11859-009-0608-8.

Yang, S., H. Ke, X. Wu, J. Tian, and J. Hou, 2005: HF radar ocean current algorithm based on MUSIC and the validation experiments. IEEE J. Oceanic Eng., 30, 601-618, https://doi.org/ 10.1109/JOE.2005.858370.

Zhang, H. G., X. L. Lou, A. Q. Shi, X. K. He, W. B. Guan, and D. L. $\mathrm{Li}, 2014$ : Observation of sand waves in the Taiwan Banks using HJ-1A/1B sun glitter imagery. J. Appl. Remote Sens., 8, 083570, https://doi.org/10.1117/1.JRS.8.083570.

Zhang, W., J. Wilkin, and H. Arango, 2010: Towards an integrated observation and modeling system in the New York Bight using variational methods. Part I: 4DVAR data assimilation. Ocean Modell., 35, 119-133, https://doi.org/ 10.1016/j.ocemod.2010.08.003.

Zhang, Y., Y. Li, H. Shao, Y. Zhong, S. Zhang, and Z. Zhao, 2012: Band gaps and localization of surface water waves over largescale sand waves with random fluctuations. Phys. Rev. E, 85, 066319, https://doi.org/10.1103/PhysRevE.85.066319. 